\title{
Optimization in a realistic structural engineering context: redesign of the Market Hall in Ghent
}

\author{
Wouter Dillen ${ }^{\mathrm{a}, *}$, Geert Lombaert ${ }^{\mathrm{b}}$, Ruben Mertens ${ }^{\mathrm{c}}$, Hanne Van Beurden ${ }^{\mathrm{d}}$, \\ Dirk Jaspaert ${ }^{\mathrm{d}}$, Mattias Schevenels ${ }^{\mathrm{a}}$ \\ ${ }^{a}$ KU Leuven, Faculty of Engineering Science, Department of Architecture, Kasteelpark \\ Arenberg 1, 3001 Leuven, Belgium \\ ${ }^{b} K U$ Leuven, Faculty of Engineering Science, Department of Civil Engineering, Kasteelpark \\ Arenberg 40, 3001 Leuven, Belgium \\ ${ }^{c}$ Currently at Mouton Engineering, Voskenslaan 171, 9000 Gent, Belgium \\ ${ }^{d} B A S$ Engineering, Diestsevest 54/2, 3000 Leuven, Belgium
}

\begin{abstract}
Structural optimization has been extensively studied for decades, motivated by expected savings in material costs and engineering efforts in the design of loadbearing structures. The potential of optimization methods in the construction sector is high, but practical applications remain scarce, which may be explained by the fact that most test problems in academic literature are not representative of reality. The aim of this article is threefold: (1) assessing possible weight savings in a realistic structural design context, (2) examining the feasibility of structural optimization accounting for all practical constraints, and (3) providing a realistic test case to developers of structural optimization algorithms. In order to simulate a real design context, the steel structure of the Market Hall in Ghent (Belgium) is optimized, taking into account all relevant Eurocode provisions and practical requirements. By maintaining the structural member groups of the original design, the dimensionality of the optimization problem is small enough to be solved by a Genetic Algorithm. Using this approach, a design is obtained that consumes $15 \%$ less material than the original design with no increase in structural complexity, implying equivalent savings in material costs and embodied environmental impact.
\end{abstract}

Keywords: Structural optimization, Size optimization, Genetic algorithm, Metaheuristic, Eurocode design, Steel design, Material minimization

\section{Introduction}

The construction sector is an important contributor to the current environmental problems. In the European Union, the built environment is responsible

\footnotetext{
*Corresponding author

Email address: wout.dillen@kuleuven.be (Wouter Dillen)
} 
for $50 \%$ of the consumption of natural resources, $42 \%$ of the total energy con5 sumption, and $35 \%$ of greenhouse gas emissions [1]. Roughly half of these emissions are attributed to the operational impacts of buildings, caused by e.g. heating, cooling, and ventilation, while the other half is attributed to embodied impacts, which are related to the production, transport, construction and disposal of building materials [2,3]. Approximately $50 \%$ of building materialrelated emissions are attributed to structural materials [4].

The relative importance of embodied impacts in the whole life environmental impact of a building is growing [5]. Recent policy interventions, backed by extensive research, have significantly reduced operational energy demands, increasing the contribution of embodied impacts to the total [6]. Current near-zero energy

15 targets will soon cause the embodied impact to approach $100 \%$ of a building's total environmental impact [7]. Emissions reduction targets will not be met unless the share of the embodied impact in buildings is reduced [8]. There are some gains that can be made by improving existing production processes, but for certain materials (e.g. metal) the production is already extremely efficient. As an 20 example, the IEA estimated that universal adoption of best practice in industry would reduce emissions from steelmaking by $13 \%$, which is insufficient to reach the Intergovernmental Panel on Climate Change's targeted $50 \%$ to $85 \%$ reductions $[9,10,11]$. Further improvements are needed, and material efficiency will play a vital role in reducing the environmental impact of the construction sector 25 to within acceptable limits [7]. The Joint Committee on Structural Safety has recently announced the initiation of a task force committed to update structural design codes in this sense, stating that "there is an urgent need to substantially reduce greenhouse gas emissions from the built environment" [12].

In current building practice, structural members are often not used to their 30 full potential. This under-utilization is the result of design rationalization: structural designers trade in material efficiency for spare capacity in order to reduce engineering efforts as well as fabrication and construction costs. Whereas a spare capacity of $5 \%$ to $20 \%$ is considered acceptable among structural engineers $[13,14,15]$, a recent study by Moynihan and Allwood on more than 3510,000 steel beams found that the average spare capacity was more than $50 \%$ in reality [15]. This discrepancy suggests that the trade-off between material efficiency and design rationalization is out of balance in current engineering practice, leaving room for considerable material savings.

Structural optimization methods are tools to improve the balance between

40 efficiency and rationalization. Moreover, these methods can be used to automate the process of selecting appropriate sections for the structural members (now often based on trial-and-error), which would reduce engineering efforts. The introduction of optimization methods in structural design practice is self-evident on paper, but turns out to be difficult in reality. There is a gap in the com-

45 plexity of design problems considered in the academic literature on structural optimization and structural engineering practice $[16,17,18]$. The academic literature puts much more emphasis on the development of new optimization algorithms than on examples of their application, as was already pointed out in the 1990s by [17]. However, a more problem-oriented approach, which focuses on 
the specific needs of structural designers, might help to introduce optimization methods in daily engineering practice.

Realistic structural optimization problems are complex. First of all, the choice of building elements is limited to commercially available options, introducing discrete design variables into the optimization problem. Secondly, all relevant building standards must be taken into account, resulting in a multitude of constraints that are often discontinuous in terms of the design variables. The discrete nature of the optimization problem prohibits the direct use of efficient gradient-based methods. When the dimensionality of the problem is small, metaheuristic methods are a viable alternative. They are easy to implement, 60 which makes them more accessible to non-experts. Their technical aspects have already been extensively studied in the academic literature and the question is no longer whether they can be applied in a realistic context, but rather why they are not applied more frequently already. The potential of structural optimization methods in the design process needs to be investigated, as well as the obstacles that prevent them from being applied in practice.

The aim of this article is to explore the feasibility and the potential of structural optimization in a practical context by means of a realistic test case: the Market Hall in Ghent (figure 1). The roof structure of this building was designed by BAS, with the support of Stabilogics, and completed in 2012. The to objective of this study is to "redesign" the original structure, minimizing the steel weight of the primary supporting structure while taking into account all technical and other constraints as considered in the original design by BAS. The scope is limited to size optimization. As in the original design, the structural members are divided into 13 groups. All members in a single group have the 75 same cross-section, which is selected from a commercial steel catalog and controlled by a single design variable. This approach has the advantage that (1) the optimized design will not be more complicated than the original design, so that possible weight savings are not obtained at the expense of increased complexity, and (2) the number of design variables is small enough for a Genetic Algorithm

so to find good solutions within a reasonable time frame. The optimized design is validated using commercial structural analysis software and presented to the structural designers, whose feedback is included in the text. The MATLAB source code used in this study has been made available as supplementary material on the Engineering Structures website.

The remainder of the article is structured as follows. Section 2 summarizes the state of the art on structural design optimization. Section 3 describes the structural design of the Market Hall in more detail. Section 4 discusses the relevant Eurocode clauses. Section 5 presents the optimization problem formulation and describes the methodology. Section 6 discusses the results of the optimiza90 tion and includes feedback from the structural designers. Section 7 presents final conclusions. 


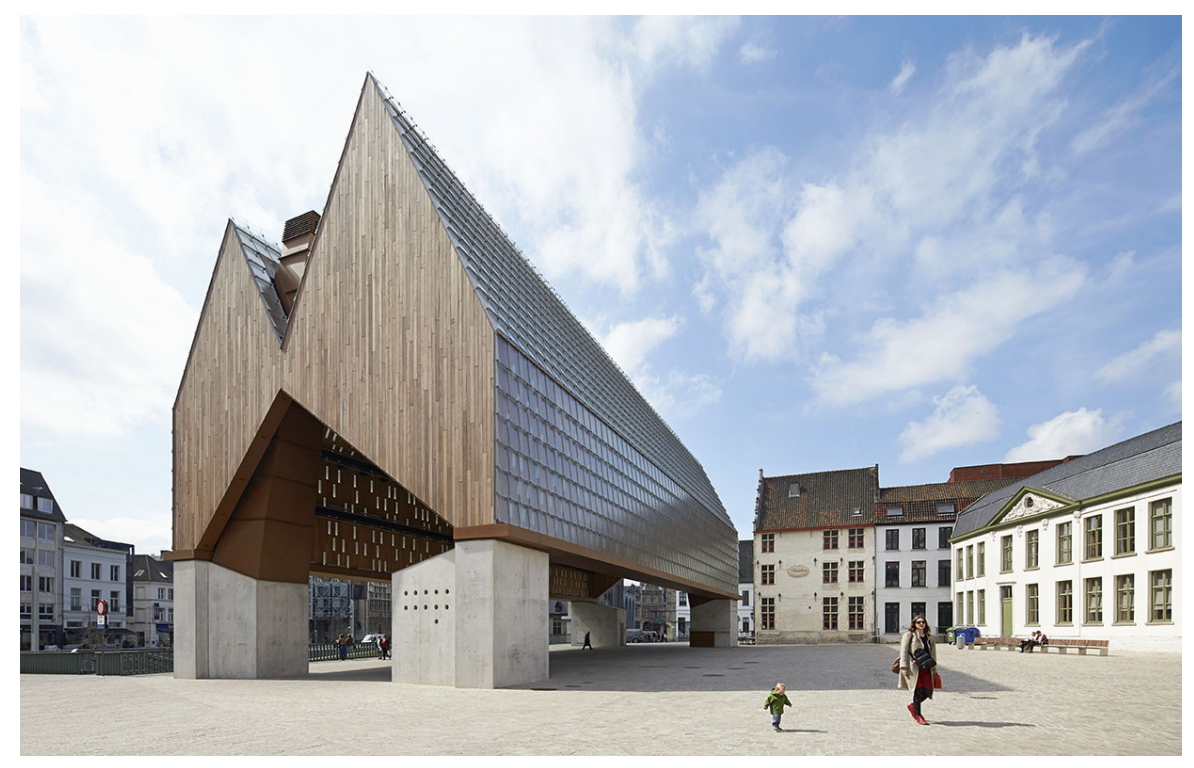

Figure 1: Outside view of the Market Hall [19].

\section{State of the art}

This section briefly describes the state of the art on (discrete) structural design optimization and on the use of structural optimization methods in practical engineering applications.

\subsection{Structural optimization}

\subsubsection{Nonlinear programming}

Optimum design of steel frames consisting of commercially available building elements falls into the category of nonlinear programming problems with linked 100 discrete design variables [20]. In a discrete context, efficient gradient-based methods such as Sequential Quadratic Programming [21], Interior-point methods [22], Trust-region methods [23], Convex Linearization [24] or the Method of Moving Asymptotes [25] are not directly applicable for finding local optima. In some cases, it is possible to convert a discrete optimization problem into a continuous problem by means of a relaxation approach, in which the design variables of the continuous optimum are rounded up or down to nearby discrete values [26]. However, the corresponding solution is not necessarily an optimum of the discrete problem; it might be sub-optimal or infeasible. Alternative approaches include heuristic optimization methods, such as the fully constrained

110 design technique by Flager et al. [27] and the discrete variant of the Optimality Criteria method by Schevenels et al. [28], or metaheuristic methods. 


\subsubsection{Metaheuristic methods}

Since 1990, the literature on discrete design optimization is dominated by metaheuristic methods [18]. Examples include Genetic Algorithms [29], Particle Swarm Optimization [30], and Simulated Annealing [31]. Characteristically, metaheuristic methods use stochastic operators to explore the search space in a pseudo-random fashion. They are easy to implement and able to handle a wide range of optimization problems, as they do not require the objective and constraint functions to be differentiable. Furthermore, metaheuristic methods are non-intrusive, in the sense that they can be combined with existing structural analysis software without changing the code, as long as the software can be called via the command line or via an API. However, metaheuristic methods also have important drawbacks: they are relatively inefficient, they have algorithmic control parameters that often affect the performance in an unpredictable way, and they tend to convergence prematurely when the number of design variables is high, which is a consequence of the curse of dimensionality [32].

Many metaheuristic methods are inspired by natural phenomena, which are appealing to the imagination and contribute to their popularity. The Genetic Algorithm (GA) is one of the first and best known metaheuristic algorithms. It has had several applications in the academic literature and has been used e.g. by Rajeev and Krishnamoorthy for discrete size optimization of structures [33] and by Rajan for combined size, shape and topology optimization of trusses with mixed design variables [34]. Over the years, many new or improved metaheuristic algorithms have appeared, but their fundamental principles are usually similar to those of existing methods [35]. For a more in-depth review, the reader is referred to the relevant literature $[36,37,38]$.

\subsection{Structural optimization in engineering practice}

Examples of structural optimization focusing on practical applications include large-scale frame structures studied by Kaveh et al. [39, 40, 41] and a steel structure subjected to seismic loading that has been optimized by Gholizadeh and Salajegheh [42]. The academic literature also includes a limited number of articles on Eurocode-based optimization. Guerlement et al. [43] applied a heuristic method to the 10-bar truss and to a simple frame structure, considering strength and displacement constraints from Eurocode 3. Jalkanen [44] applied several metaheuristic methods to the size, shape and topology optimization problem of tubular trusses subject to the constraints in Eurocode 3. Mela [45] integrated member constraints specified by Eurocode 3 in the MILP formulation for truss topology design, with extensions by Van Mellaert et al. [46, 47] for joint constraints and frame structures. Brütting et al. [48] applied a similar strategy

150 to the design of truss structures, selecting bars from a predefined stock of reclaimed structural components. Finally, D'Amico and Pomponi [49] presented a fully utilized design-like heuristic method for minimizing material consumption in steel frames with rectangular layouts and constant span lengths.

Even though structural optimization has been studied intensively for 155 decades, its applications in the construction sector remain scarce. Vierlinger et 
al. have used a GA to find the optimal placement of prefab V-shaped columns in the design of a sustainable apartment building in Vaduz, Liechtenstein, taking into account constraints on the horizontal and vertical deflections while avoiding over-utilization of the columns [50]. Richardson et al. have used a multiobjective GA to optimize the bracing system of a museum building in Washington, D.C. in the United States, limiting the horizontal deflections but excluding the other building code provisions [51]. Still, the majority of publications on physical examples involve highly specialized applications or eye-catching prototypes. It is concluded that the gap between theory and practice, which has been noted over 25 years ago [17], has not yet been closed, despite promising studies on the potential impact of using optimization techniques in the construction sector $[11,10,5]$.

\section{Structural design of the Market Hall}

The Market Hall is located on the Emile Braun Square, forming the centrepiece of the master plan for the redesign of the central squares in Ghent, Belgium. Its open roof is inspired by the old town market places of the Middle Ages and serves as a venue for markets and concerts. The building was designed by local architects Robbrecht \& Daem and Marie-José Van Hee, and the structure of the roof was engineered by BAS and further refined by Stabilogics

175 during the execution phase. The project was completed in 2012 and received both criticism and acclaim, leading to a nomination for the Mies van der Rohe Award in 2013.

\subsection{Geometry}

The Market Hall has a rectangular floor plan and is point-symmetrical around the center. Its roof is about $39 \mathrm{~m}$ long and $15 \mathrm{~m}$ wide, rising $16 \mathrm{~m}$ above the four $4.5 \mathrm{~m}$ concrete abutments at the corners. The right-hand side of the front façade is larger than the left-hand side, making the gutter beam run diagonally between the two roof sections when seen from above. Two chimney vents are positioned on the lower sides of the roof, surrounded by trimmer constructions. Smoke hatches are located on the opposite sides, which do not affect the shape of the primary supporting structure.

The roof is designed as a reticulated folding structure, which spans in the longitudinal direction and is supported at the corners. The outer walls are covered in dark afrormosia wood and pierced by 1550 skylights. The supporting structure consists of a steel frame with diagonal tie rods for added in-plane stiffness. The front façades are designed as three-hinged arches. Three horizontal Vierendeel girders have been installed on each of the side walls to provide lateral stiffness in order to absorb the wind loads and thrust forces and thus limit lateral displacements. The structural height of the upper two Vierendeel girders is variable, increasing towards the middle of the span. The structure is composed of standard HE sections (type A, B and M) for the main frame, square hollow sections (SHS) for the Vierendeel girders, the lower edges of the 


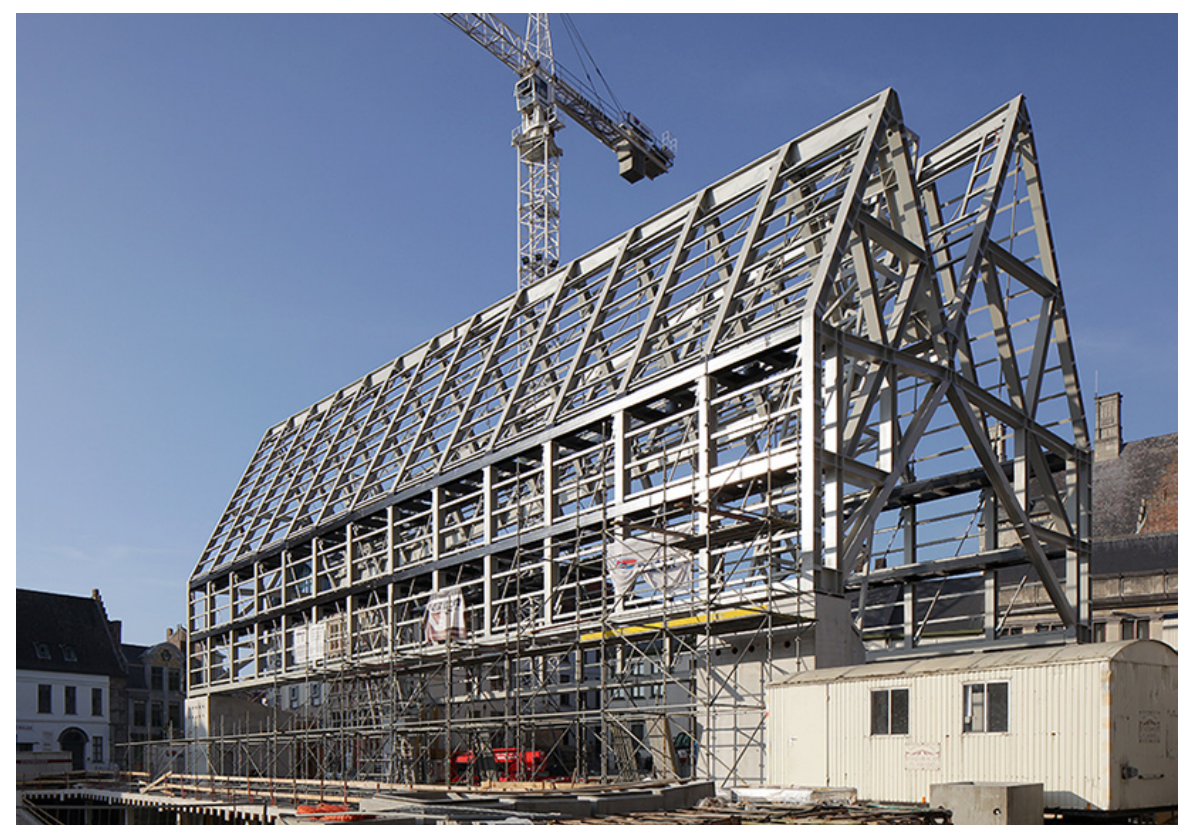

Figure 2: The roof during construction [52].

front façades and the ridge and gutter beams, and round bars ( $\mathrm{R}$ ) for the tie rods. The horizontal purlins in the roof surfaces (HE $100 \mathrm{~A}$ ) are meant to fix the cladding and are not supposed to contribute to the primary supporting structure. Only a small fraction of the structure has been left uncovered, making it an ideal candidate for size optimization without changing the appearance of the building.

\subsection{Boundary conditions}

Figure 3 shows how the boundary conditions are modelled. The roof is mounted on four concrete abutments, each of which supports four nodes of the steel structure. In the vertical direction, the abutments are modelled by means of spring-loaded bearings with spring stiffness equal to $550 \times 10^{3} \mathrm{kN} / \mathrm{m}$. In the horizontal direction, the displacements at the supports are fixed, except for the longitudinal displacements of the nodes facing the chimneys, allowing for thermal expansion.

\subsection{Material properties}

Isotropic linear-elastic material behaviour is assumed in accordance with Hooke's law. The material properties of structural steel are taken from 215 [EC3: §3.2.6], with modulus of elasticity $E=210 \mathrm{GPa}$ and Poisson's ratio $\nu=0.3$. The density of the steel is $\rho=7851.8 \mathrm{~kg} / \mathrm{m}^{3}$. The yield strength 


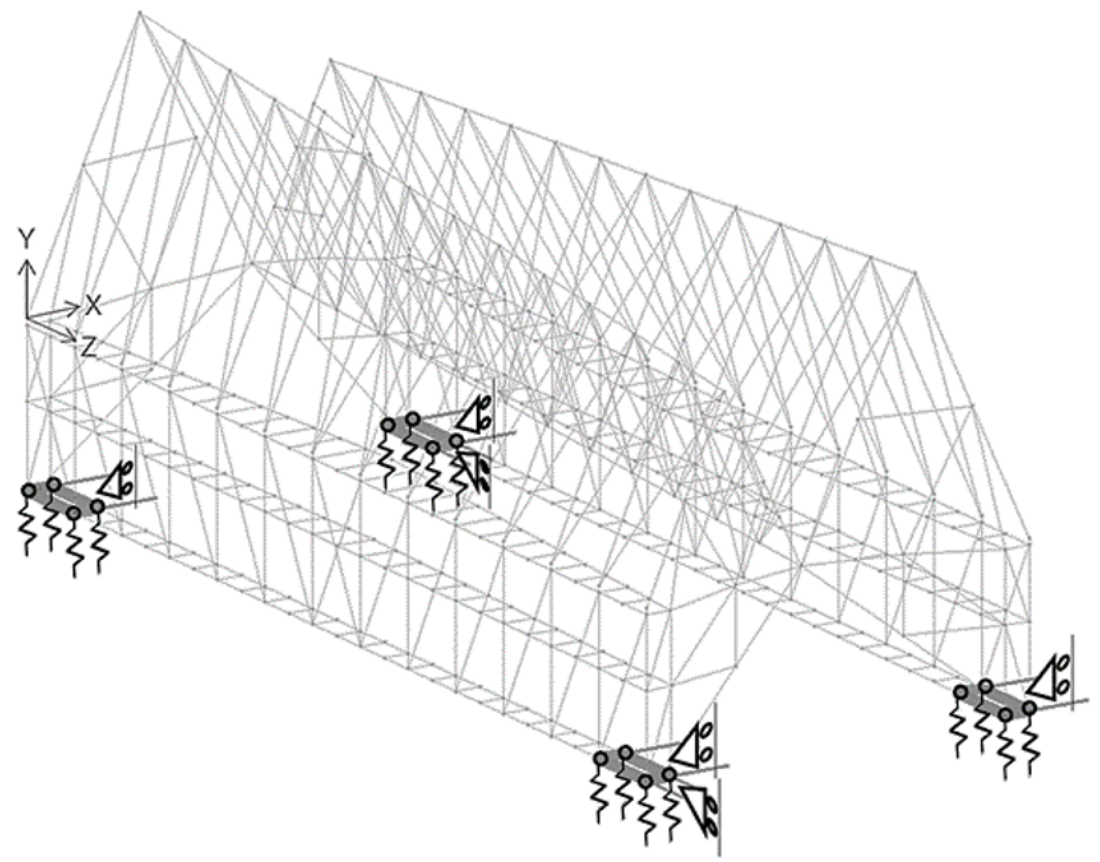

Figure 3: The supports.

is determined in accordance with the steel grade, which is S235, S355 and S460 for the HE, SHS and R sections, respectively.

\subsection{Structural analysis}

The structural analysis of the Market Hall is performed using the finite element method [53]. The original structural model was implemented by BAS in PowerFrame (now called Diamonds), a commercial finite element package developed by BuildSoft. However, this model is too slow when called a high number of times by iterative optimization solvers. An equivalent structural model has therefore been implemented in MATLAB, based on the Stabil toolbox for finite elements [54]. The nature of the structural analysis is preserved: the geometry, loads, and boundary conditions were imported from the reference model in Diamonds. The implementation in MATLAB is limited to the applicable Eurocode clauses for this specific case and optimized for computational efficiency, making it several orders of magnitude faster than Diamonds.

The finite element model consists of 432 nodes and 837 three-dimensional Euler-Bernoulli beam and bar ${ }^{1}$ elements, which are connected using either rigid

\footnotetext{
${ }^{1}$ The tie rods are modelled as bar elements to make linear analysis possible. The bar elements are positioned such that they are loaded almost exclusively in tension. For the
} 
or hinged joints depending on their position in the structure (figure 4). The system of equilibrium equations has 3136 degrees of freedom in total. The member end forces and displacements are interpolated using the appropriate shape functions and taking into account the effect of distributed loads in order to obtain intermediate values in 11 points that are spaced evenly along the length of the members. The intermediate force and displacement values will be used in the Eurocode (EC) checks in the following section. No Eurocode checks are performed for certain small elements (shown in red on figure 4) that are used to model eccentricities in the joints or the transition to the supports.

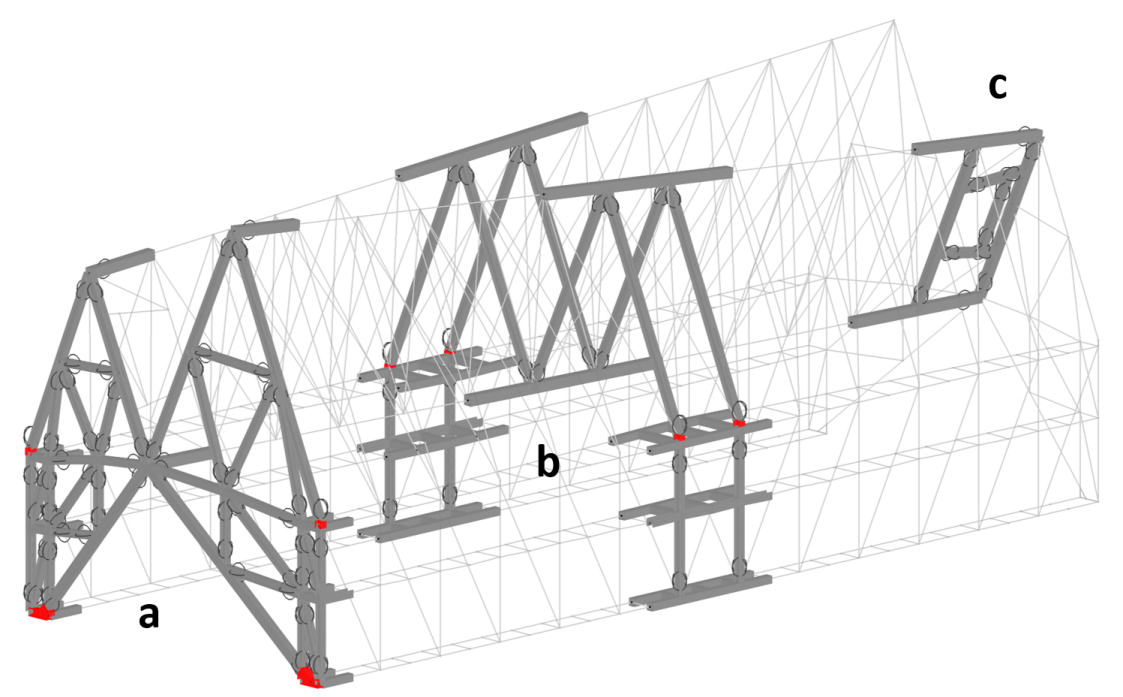

Figure 4: Examples of hinged connections in (a) the front façades, (b) the main span and (c) the trimmer constructions. The elements for which no Eurocode checks apply are shown in red.

\section{Eurocode design}

This section discusses the Eurocode clauses that are included as constraints in the optimization problem. The implementation in MATLAB closely follows the reference model in Diamonds. This section mainly refers to EN 1993-1-1 NL (2015), the general rules for the design of steel structures (EC3), and EN 1993-11 ANB:2018, the Belgian National Annex to Eurocode 3 (ANB). The essential ideas and equations are given in the main text, while additional information

crossing elements in the middle bay, the stiffness is halved, so that the combined effect of compression and tension corresponds to that of a single tie rod in tension. The effect of these simplifications has been assessed and was found to be negligible. 
is given in appendix B. In the following sections, the loads on the structure 250 are discussed first, followed by the verification of strength and stability of the structure in the Ultimate Limit State and deformations in the Serviceability Limit State.

\subsection{Load cases}

Ten load cases were imported from Diamonds, including two permanent actions (self-weight and permanent load) and eight variable actions (lighting equipment, snow load and wind load). The wind load consists of six scenarios for wind blowing in different directions (making use of symmetry), combined with upward or downward wind pressures, with the aim of obtaining a representative impression of the effects of wind on the structure.

\subsection{Combination of actions}

The effect of the individual actions has to be combined according to the procedure in Eurocode 0. Depending on the nature of the load, its contribution should be in- or decreased by a partial factor $\gamma$ and/or $\psi$. In this study, the combination of actions is based on the reference model in Diamonds, where 212 combinations are defined in the Ultimate Limit State, corresponding to the fundamental combination of actions [EC0 §6.4.3.2]:

$$
\sum_{j \geq 1} \gamma_{G, j} G_{k, j} "+" \gamma_{Q, 1} Q_{k, 1} "+" \sum_{i>1} \gamma_{Q, i} \psi_{0, i} Q_{k, i}
$$

and 53 combinations are defined in the Serviceability Limit State, corresponding to the characteristic combination of actions [EC0 $§ 6.5 .3 \mathrm{a}]$ :

$$
\sum_{j \geq 1} G_{k, j} "+" Q_{k, 1} "+" \sum_{i>1} \psi_{0, i} Q_{k, i} .
$$

In these equations, the symbol "+" implies "to be combined with", and " $\sum$ " implies "the combined effect of". The terms $\gamma_{Q, 1} Q_{k, 1}$ and $\gamma_{G, j} G_{k, j}$ represent the design values of the leading variable action and the permanent actions, respectively, whereas the terms $\gamma_{Q, i} \psi_{0, i} Q_{k, i}$ represent the design combination values of the accompanying variable actions. The term for prestressing actions has been left out in both equations. The Market Hall is classified as category $\mathrm{C}$ (congregation areas), with Consequences Class 2 and a design working life of 50 years, leading to the values for the partial factors $\gamma$ and $\psi$ listed in table 1 .

\subsection{Global analysis}

The internal forces and displacements in the structure are determined using elastic global analysis. Accordingly, certain assumptions have been made. No initial sway imperfections (to account for the P- $\Delta$ effect) have been taken into account under the assumption that $H_{E d} \geq 0.15 V_{E d}$, where $H_{E d}$ is the horizontal load and $V_{E d}$ the vertical load on the building [EC3: §5.3.2(4)B]. Due to the high wind loads, this criterion is almost always met. The effect of local 
bow imperfections (P- $\delta$ effect) is accounted for in the checks for buckling resistance of members, which are discussed later in this section [EC3: §5.3.4]. The dynamic response of the structure, failure of the foundations, and fatigue are disregarded, as are the effects of eccentricity and flexibility of the connections and the geometrical conditions for welding in EN 1993-1-8. As a practical rule of thumb, a member utilization ratio of $90 \%$ is pursued (as suggested by BAS), leaving a margin for stress concentrations in the joints. This rule of thumb is used to set the limits for the constraints in section 5 .

\subsection{Ultimate Limit State}

The Eurocode standards are based on limit state design to determine whether a structure meets the relevant design criteria. The Ultimate Limit State (ULS) is used to verify the safety of the structure, by showing that all members comply with the engineering demands for strength and stability under the relevant design loads. Appropriate magnification and reduction factors are applied to the loads and resistances in order to account for statistical uncertainty. The stresses in the members are divided by the relevant resistances in order to obtain utilization ratios (UR), which must be smaller than one for the design to be feasible. The utilization ratios limit the design space and act as constraints to the optimization problem.

\section{4.4.1. Reduced yield strength}

Material imperfections (e.g. residual stresses) may negatively affect the yield strength of the steel. The risk of residual stresses increases as the steel becomes thicker. This effect is taken into account by means of a reduced yield strength for sections with a nominal thickness (equal to the flange thickness) of more

300 than $16 \mathrm{~mm}$, the values of which are based on tables 3.3 and 3.4 in the Belgian National Annex to EC3. Reduced yield strength values are adopted for the HE and SHS sections, but not for the $\mathrm{R}$ sections, as no reduction was found in the original model of BAS.

\subsubsection{Classification of cross-sections}

305 Structural members loaded in compression may not be able to attain their full capacity in strength, as thin parts of the cross-section may lose stability before a plastic hinge can develop. Depending on the geometry of the cross-section and the (reduced) yield strength of the steel, a distinction is made between four classes of cross-sections. Each part of the cross-section (wall, flange or web) is separately classified according to [EC3: $\$ 5.5$ \& Table 5.2] on the basis of the width-to-thickness ratio of the area in compression. The highest class of the compression parts determines the class of the entire cross-section. Depending on the class, the checks in ULS must be based on plastic (Class 1 and 2), elastic (Class 3) or effective section properties (Class 4).

The structure of the Market Hall consists exclusively of uniform members with doubly symmetric cross-sections, which can be classified prior to the analysis on the level of the profile catalog. The classification is carried out separately 
for the case of uniform compression and bending about both principal axes. Which of these cases is normative depends on the distribution of axial forces 320 and bending moments in each individual member. The highest class for bending is used to determine which formula to use for checks that involve combined actions, after which the resistance of the cross-section is computed on a case-bycase basis for each individual action (using effective section properties for the verification of Class 4 cross-sections).

\subsubsection{Resistance of cross-sections}

The resistance of the structure is verified on the level of the individual members in accordance with [EC3: $§ 6.2]$. The utilization ratios for the resistance of the cross-sections are evaluated in 11 interpolation points that are evenly spaced along the longitudinal axis. The design value of the yield strength is:

$$
f_{y d}=\frac{f_{y k}}{\gamma_{M 0}}
$$

with partial resistance safety factor $\gamma_{M 0}=1$ for buildings [EC3: $\S 6.1(1)$ note 2B]. The effect of the individual forces and moments is considered first [EC3: $\S 6.2 .3$ to $\S 6.2 .7]$, where the tie rods are tested for their capacity in tension only. In the equations that follow, $F_{E d}$ denotes the design absolute value of the relevant force or moment. The index $i=y, z$ indicates the axis parallel to which a force acts or about which a member bends. The utilization ratio for the axial forces is:

$$
\mathrm{UR}_{R, N}=\frac{N_{E d}}{N_{p l, R d}}, \quad \text { with } N_{p l, R d}=A f_{\mathrm{yd}}
$$

where $A$ represents the area of the cross-section (with $A=A_{\text {eff }}$ for Class 4 cross-sections in compression). The utilization ratio for torsion is:

$$
\mathrm{UR}_{R, T}=\frac{T_{E d}}{T_{R d}}, \quad \text { with } T_{R d}=\frac{T_{e l, t} f_{y d}}{\sqrt{3}}
$$

where $T_{e l, t}$ is the section modulus for St. Venant torsion, ignoring the effect of warping. The utilization ratio for shear is:

$$
\mathrm{UR}_{R, V, i}=\frac{V_{i, E d}}{V_{p l, i, R d}}, \quad \text { with } V_{p l, i, R d}=\frac{A_{v, i} f_{y d}}{\sqrt{3}}
$$

where $i=y, z$ and $A_{v}$ is the shear area. Both the axial forces and the shear forces may negatively affect the bending resistance. In the case of Class 1 and 2 cross-sections, this effect is accounted for by means of a reduced moment resistance $M_{N V, i, R d}$. Accordingly, the utilization ratios for uni-axial bending are:

$$
\mathrm{UR}_{R, M, i}=\frac{M_{i, E d}}{M_{N V, i, R d}}
$$


and those for bi-axial bending are:

$$
\mathrm{UR}_{R, C, 1,2}=\left(\frac{M_{y, E d}}{M_{N V, y, R d}}\right)^{\alpha}+\left(\frac{M_{z, E d}}{M_{N V, z, R d}}\right)^{\beta}
$$

with $\alpha$ and $\beta$ according to [EC3: $§ 6.2 .9 .1(6)]$. The resistance checks for Class 3 and 4 cross-sections are based on a linear combination of the longitudinal stresses, so that uni-axial bending will never be decisive. Instead, the following interaction formula for bi-axial bending is used:

$$
\mathrm{UR}_{R, C, 3,4}=\frac{N_{E d}}{N_{p l, R d}}+\frac{M_{y, E d}}{M_{V, y, R d}}+\frac{M_{z, E d}}{M_{V, z, R d}}
$$

with $N_{p l, R d}$ the same as in equation (4) and $M_{V, i, R d}$ the reduced bending resistance due to the shear force [EC3: $§ 6.2 .9 .2(1) \mathrm{P}]$. Details on the calculation of the reduced bending resistance $M_{V, i, R d}$ and $M_{N V, i, R d}$ are given in appendix B.

\subsubsection{Imperfection factors}

In the following, the stability of the members is evaluated. For uniform members with doubly symmetric cross-sections, loss of stability due to axial compression can manifest itself in three different ways: flexural buckling about the strong axis, flexural buckling about the weak axis, and torsional buckling about the longitudinal axis. In reality, only the buckling mode that corresponds to the lowest buckling resistance will occur, after which the member loses stability. For members susceptible to torsional deformations, lateral-torsional buckling may in addition occur when the bending moment about the strong axis exceeds a certain critical value, resulting in simultaneous lateral displacement and twisting of the cross-section.

To account for buckling of the members, a reduction factor $\chi$ is applied to the resistance of all members loaded (partially) in compression. The reduction factor $\chi$ is based on the theoretical critical buckling load and takes into account the adverse effect of imperfections (residual stresses, eccentricities, variability of the yield strength, etc.) through an imperfection factor $\alpha$. The value of this mperfection factor depends on the geometry of the cross-section, the production process, and the grade of the steel. Each value of $\alpha$ corresponds to one of the empirical buckling curves given in [EC3: Tables 6.2 \& 6.1] (flexural and torsional buckling) and [EC3: Tables 6.4 \& 6.3] (general method for lateral-torsional buckling).

\subsubsection{Buckling lengths}

The critical buckling load of a member depends on the buckling length $L_{c r}$, which has to be determined from the length of the member, the characteristics of the structure, and the stiffness of the joints. The buckling lengths of the members of the Market Hall are taken as equal to the system lengths, with reductions for truss members according to [EC3: $§ B B .1]$ and with the exception of the Vierendeel web and inner chord members, for which the out-of-plane 
buckling lengths are taken as twice and half the system length, respectively. After an initial optimization, one of the ridge beams turned out to be sensitive to global buckling, so a more detailed buckling length calculation was performed in Diamonds for the affected members based on the stiffness of the surrounding structure $^{2}$. The approach is as follows: individually for each member or system of members, an evenly distributed load is applied in the plane of the relevant buckling mode. The structural response is analyzed, obtaining values for the translation, rotation, shear force and bending moment at the member's ends. The resulting values serve as the boundary conditions for the homogeneous beam equation:

$$
E I \frac{d^{4} w}{d x^{4}}+P \frac{d^{2} w}{d x^{2}}=0
$$

where $w(x)$ is the lateral beam deflection. The first $n$ non-trivial solutions to this equation represent the first $n$ buckling modes of the beam. The critical buckling load $P_{c r}$ is obtained as the load that corresponds to the first buckling mode. The buckling length $L_{c r}$ is then computed using Euler's critical load formula:

$$
P_{c r}=\frac{\pi^{2} E I}{L_{c r}^{2}} .
$$

Accordingly, a buckling length of $L_{c r, y}=L_{c r, z}=13 \mathrm{~m}$ was assigned to the members in the ridge and gutter beams.

\subsubsection{Buckling resistance of members}

The design value of the yield strength in the stability checks is:

$$
f_{y d}=\frac{f_{y k}}{\gamma_{M 1}}
$$

again with $\gamma_{M 1}=1$ [EC3: $\S 6.1(1)$ note $\left.2 \mathrm{~B}\right]$. The terms $N_{E d}, M_{y, E d}$ and $M_{z, E d}$ represent the design values of the compression force and bending moments, evaluated in the same 11 interpolation points as for the resistance checks. No instability checks are performed for the tie rods, as they are supposed to act in tension only. The utilization ratios for flexural buckling (equation 13) and torsional buckling (equation 14) are computed as:

$$
\begin{aligned}
\mathrm{UR}_{S, N, i} & =\frac{N_{E d}}{N_{b, i, R d}}, \quad \text { with } N_{b, i, R d}=\chi_{i} A f_{y d} \\
\mathrm{UR}_{S, N, T} & =\frac{N_{E d}}{N_{b, T, R d}}, \quad \text { with } N_{b, T, R d}=\chi_{T} A f_{y d}
\end{aligned}
$$

\footnotetext{
${ }^{2}$ The buckling length of the ridge and gutter beams is difficult to determine in advance, as they are partly supported by slanted rafters that make an angle of about 25 degrees with the vertical axis. As an alternative to the approach in the main text, the buckling lengths of the ridge and gutter beams can be (conservatively) taken as the system length or else selected based on engineering judgment.
} 
with $i=y, z, A$ the area of the cross-section, and $\chi$ the reduction factor for the relevant buckling mode [EC3: §6.3.1.2]. The reduction factors depend on the elastic critical force $N_{c r}$, which is obtained from [ANB: Annex F] based on the buckling length of the member and the gross cross-section properties:

$$
\begin{aligned}
& N_{c r, i}=\frac{\pi^{2} E I_{i}}{L_{c r, i}^{2}}, \quad \text { with } i=y, z \\
& N_{c r, T}=\frac{A}{I_{y}+I_{z}}\left(G I_{T}+\frac{\pi^{2} E I_{w}}{L_{c r, L T}^{2}}\right) .
\end{aligned}
$$

A detailed calculation of the reduction factors $\chi$ is given in appendix B. The utilization ratio for lateral-torsional buckling is computed as follows:

$$
\mathrm{UR}_{S, M, L T}=\frac{M_{y, E d}}{M_{b, y, R d}}, \text { with } M_{b, y, R d}=\chi_{L T} W_{y} f_{y d}
$$

with section modulus $W_{y}=W_{p l, y}$ for Class 1 and 2 cross-sections, $W_{e l, y}$ for Class 3 cross-sections and $W_{e f f, y}$ for Class 4 cross-sections, and reduction factor for lateral-torsional buckling $\chi_{L T}$ according to the general method in [EC3: §6.3.2.2]. The reduction factor $\chi_{L T}$ depends on the elastic critical moment $M_{c r}$, which is computed in accordance with [ANB: Annex E.3(3)], assuming hinged supports and free bending of the member:

$$
M_{c r}=C_{1} \frac{\pi^{2} E I_{z}}{L_{c r, L T}^{2}} \sqrt{\frac{I_{w}}{I_{z}}+\frac{L_{c r, L T}^{2} G I_{T}}{\pi^{2} E I_{z}}} .
$$

In this equation, $C_{1}$ is the equivalent uniform moment factor for lateral-torsional buckling. The implementation in Diamonds deviates from the Eurocode and computes $C_{1}$ using the following formula, proposed by Serna et al. [55]:

$$
C_{1}=\sqrt{\frac{35 M_{\max }^{2}}{M_{\max }^{2}+9 M_{2}^{2}+16 M_{3}^{2}+9 M_{4}^{2}}},
$$

where $M_{\text {max }}$ is the maximum bending moment and $M_{2}, M_{3}$ and $M_{4}$ the bending moment at points $L / 4, L / 2,3 L / 4$ in a member with length $L$. For members that are not susceptible to torsional deformations, $\chi_{L T}=1$.

The utilization ratios for in-plane and out-of-plane buckling of a member due to combined bending and compression are the following [EC3: §6.3.3(4)]:

$$
\begin{aligned}
\mathrm{UR}_{S, C, y} & =\frac{N_{E d}}{\chi_{y} N_{p l, R d}}+\frac{k_{y y}}{\chi_{L T}} \frac{M_{y, E d}}{M_{y, R d}}+k_{y z} \frac{M_{z, E d}}{M_{z, R d}}, \\
\mathrm{UR}_{S, C, z} & =\frac{N_{E d}}{\chi_{z} N_{p l, R d}}+\frac{k_{z y}}{\chi_{L T}} \frac{M_{y, E d}}{M_{y, R d}}+k_{z z} \frac{M_{z, E d}}{M_{z, R d}},
\end{aligned}
$$

where $N_{E d}, M_{y, E d}, M_{z, E d}$ are the design values of the compression force and maximum bending moments about the strong and weak axis, respectively, $\chi_{y}, \chi_{z}$ 
the reduction factors for flexural buckling, $\chi_{L T}$ the reduction factor for lateraltorsional buckling, and $k_{y y}, k_{y z}, k_{z y}, k_{z z}$ interaction factors. The design compression resistance $N_{p l, R d}$ is the same as in equation (4), and the design bending resistance $M_{i, R d}=W_{i} f_{y d}$, where $W_{i}$ is the appropriate section modulus. EC3 provides two ways to calculate the interaction factors (Annex A and Annex B), but the Belgian National Annex requires the use of the former and provides further details in [ANB: Annex D]. Details on the calculation of the interaction factors are given in appendix B of this article. The interaction factors become complex numbers if one of the critical buckling loads is exceeded, in which case the utilization ratio of the corresponding interaction effect is set to a flat rate of $\mathrm{UR}_{S, C, i}=1.5$.

\subsection{Serviceability Limit State}

The Serviceability Limit State (SLS) is used to check whether the structure is suitable for its intended use under daily loading. In this regard, the deformations that are caused by the action of characteristic (un-factored) design loads must not exceed certain predefined limit values, agreed upon by the parties involved in the project. For the Market Hall, a distinction is made between the total deformations $\delta_{t o t}$ and the deformations due to the effect of variable actions $\delta_{\text {var }}$, which is obtained by subtracting the effect of the permanent actions (selfweight and permanent load) from the total. Accordingly, the utilization ratios in SLS are expressed as:

$$
\mathrm{UR}_{\delta}=\frac{\delta_{E d}}{\delta_{l i m}},
$$

where $\delta_{E d}$ represents the design deformation value and $\delta_{\text {lim }}$ the corresponding limit value.

\subsubsection{Local deformations}

The deflection of the individual members is limited to $L / 300$, where $L$ is the member length. The utilization ratios are based on the total deformations $\delta_{\text {tot }}$.

\subsubsection{Global deformations}

The deformations of the overall structure are verified in a number of critical points, located on the front façades and at the middle of the span (figure 5). The limit values for these deformations follow mainly from strict requirements on the appearance of the structure and the sense of safety of the occupants. For the deformations in the transverse direction, the original requirement of $\delta_{X, \text { lim }}=30 \mathrm{~mm}$ has not been met in all critical points. For the points where the displacement limit is violated, the limit value $\delta_{X, l i m}$ is set to the displacements that were observed in the reference model. The resulting displacement limits are shown in table 3 on page 38 . 


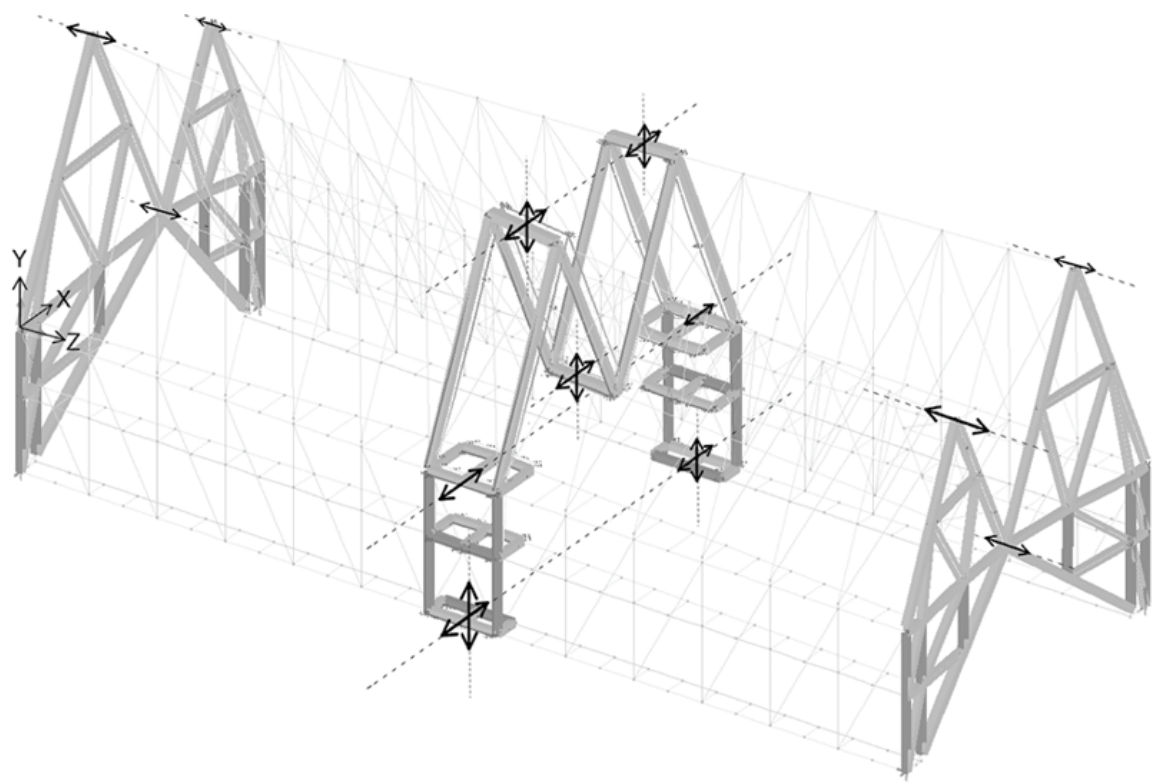

Figure 5: Verification of global deformations: critical points.

\subsection{Verification of the model}

The internal forces and displacements in MATLAB match very well with those in the reference model in Diamonds. Similarly, the Eurocode check values in both models correspond very well, with differences generally limited to a few percentage points. Among the very few exceptions are the interaction checks near the trimmer constructions, which are due to the accumulation of small errors. However, as the corresponding member groups are small (they contain few members) and the checks in MATLAB are usually more conservative, these inconsistencies are considered acceptable.

\section{The optimization problem}

The following paragraphs present the formulation of the optimization problem and describe some additional practical and architectural demands.

\subsection{Problem statement}

The optimization problem at hand is a discrete size optimization problem with nonlinear inequality constraints. The objective is to find the set of standardized steel sections that minimizes the weight of the primary supporting structure. The structure is subject to the Eurocode constraints presented in 
section 4. Formally, the problem is formulated as follows:

$$
\begin{array}{ll}
\underset{\mathbf{x}}{\operatorname{minimize}} & W(\mathbf{x})=\rho \sum_{e=1}^{N} A_{e}(\mathbf{x}) L_{e} \\
\text { subject to } & \mathrm{UR}_{R, \text { cepl }}(\mathbf{x})-0.9 \leq 0 \\
& \mathrm{UR}_{S, \text { cepl }}(\mathbf{x})-0.9 \leq 0 \\
& \mathrm{UR}_{\delta, p l}(\mathbf{x})-1 \leq 0 \\
& x_{i}^{\min } \leq x_{i} \leq x_{i}^{\max },
\end{array}
$$

where $\mathbf{x}$ is a vector collecting the design variables $x_{i}, \rho$ is the density of the steel, $N$ is the number of structural members, and $A_{e}$ and $L_{e}$ are the cross-sectional area and the length of member $e$. The design variables are limited by lower and upper bounds $x_{i}^{\mathrm{min}}$ and $x_{i}^{\max }$. The terms $\mathrm{UR}_{R, c e p l}, \mathrm{UR}_{S, c e p l}$ and $\mathrm{UR}_{\delta, p l}$ represent the utilization ratios for strength, stability and serviceability, respectively, evaluated for check $c$, member $e$, point $p$ and load combination $l$. Local deformations are not monitored during the optimization process, but they are checked afterwards. The constraints are integrated in the objective function by means of a penalization strategy, in which the original problem is reformulated as an equivalent, unconstrained optimization problem with penalized objective function $W_{p}(\mathbf{x})$ :

$$
W_{p}(\mathbf{x})=W(\mathbf{x})\left(1+\kappa_{R} C_{R}+\kappa_{S} C_{S}+\kappa_{\delta} C_{\delta}\right)
$$

where

$$
\begin{aligned}
C_{R} & =\sum_{e} \max \left(0, \max _{c, p, l}\left(\mathrm{UR}_{R, c e p l}(\mathbf{x})\right)-0.9\right) \\
C_{S} & =\sum_{e} \max \left(0, \max _{c, p, l}\left(\mathrm{UR}_{S, c e p l}(\mathbf{x})\right)-0.9\right) \\
C_{\delta} & =\sum_{p} \max \left(0, \max _{l}\left(\mathrm{UR}_{\delta, p l}(\mathbf{x})\right)-1\right)
\end{aligned}
$$

and where $\kappa_{R}, \kappa_{S}$ and $\kappa_{\delta}$ are penalty coefficients, similar to the ones in Rajeev and Krishnamoorthy [33]. The coefficients $C$ are computed on the basis of the highest UR-value along each member, summed over all members and all Eurocode checks.

\subsection{Design variables}

The members of the structure are divided into 13 member groups, each of which is assigned one discrete design variable. The value of the design variable corresponds to the index in a series of selected profiles (see appendix A). The available profiles are selected from the ArcelorMittal profile catalog (in accordance with [EN 10365: 2017]) for the HE and R sections, and from the product standard [EN 10210-2: 2006] for the SHS sections. The options are limited to 57 HE type A, B and M sections (ranging from HE 100 A to HE $600 \mathrm{M}$ ), 44 options for the full round $\mathrm{R}$ sections (all commercial sections from R 30 to $\mathrm{R} \mathrm{110}$ ), and 48 options for the square box sections (from SHS $180 \times 5$ to SHS $400 \times 20$ ). 


\subsection{Additional demands}

Two additional requirements are taken into account. The sections of the Vierendeel web members (G9) are required to be no larger than the chord members they are attached to (G7 \& G12) to avoid unrealistic joints. Additionally, the side dimensions of the HE and SHS sections must not be larger than in the original design in order to meet the architect's requirement for a slender-looking structure.

\section{Results and discussion}

\subsection{Results}

The optimization problem that is presented in the previous section is solved using the built-in GA in MATLAB R2019a, using default control parameter settings. The penalty coefficients $\kappa_{R}, \kappa_{S}, \kappa_{\delta}$ are set to 10 , as in Rajeev and Krishnamoorthy [33]. The GA is restarted 10 times with random starting points to compensate for the effect of the stochastic operators. The convergence history of the optimization runs is shown in figure 6 . The original design of the roof structure weighs 226.6 tons (figure 7 ), while the optimized designs weigh $192.7,192.7,192.8,193.2,194.8,194.9,195.4,195.9,200.9$ and 202.3 tons. The design with the lowest objective function value is shown in figure 8 . With this design, the optimizer has managed to achieve a weight reduction of $15 \%$, using the same member groups as in the original design - i.e. with no increase in structural complexity.

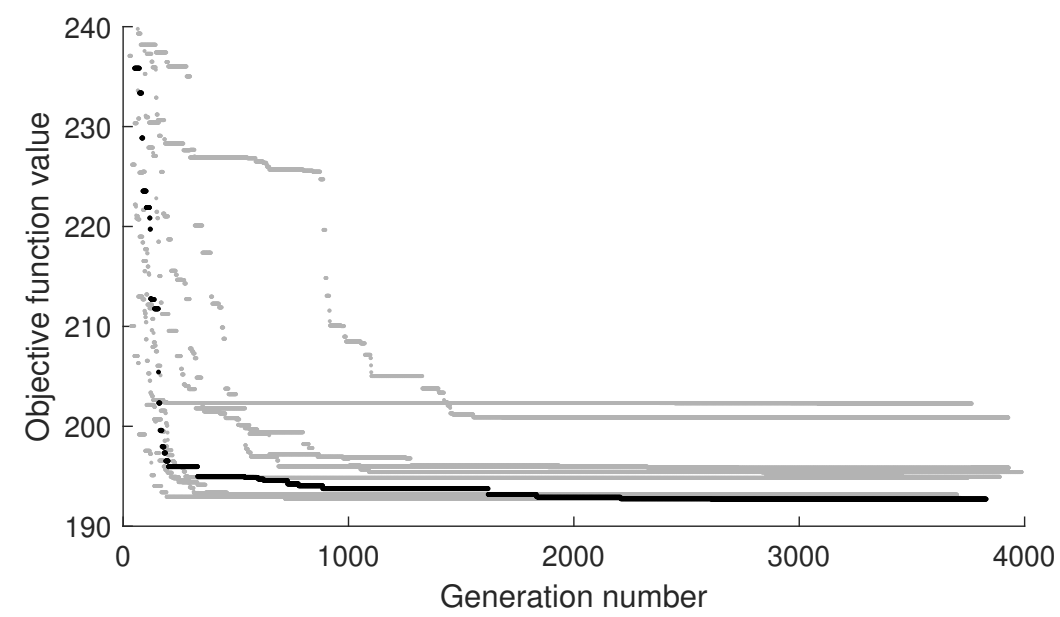

Figure 6: Convergence history of all 10 optimization runs. The optimization run that resulted in the lowest objective function value is shown in black. 


\subsection{Verification}

In what follows, the design with the lowest weight (shown in figure 8) will be referred to as the optimized design. The cross-sections of the members in the original and the optimized design are compared in table 2. As a validation, the optimized design is evaluated in Diamonds (version 2019) using linear firstorder analysis. The resulting utilization ratios for the resistance (max. 89.0\%) and stability ( $\max .85 .6 \%$ ) checks are shown in figures 10 and 12 , whereas the utilization ratios for the original design (max. $82.7 \%$ and $77.7 \%$ ) are shown in figures 9 and 11. The figures show that the limit value of $90 \%$ is never exceeded. The global deformations of the structure (table 3 ) meet the requirements in all critical points, and the individual member deflections are at most $64.7 \%$ of

445 their allowable values (while in the original design this is at most $44.2 \%$ ). All additional requirements have been met as well: the width and height of the cross-sections in G9 are not larger than those in G7 and G12 and the side dimensions of the cross-sections are never larger than in the original design.

Although linear first-order analysis is a widely used tool in the design phase of a building, it may not provide an accurate representation of reality and more sophisticated forms of analysis may apply. Accordingly, the optimized design is evaluated with tie rods instead of bar elements, using non-linear first-order analysis. The response of the structure was found to be slightly different, mainly due to the small tie rods in the trimmer constructions, causing the displacements

455 in the lateral direction to exceed the limit values (in both the original and the optimized design, see table 3$)$. The maximum $\mathrm{UR}_{R}(88.9 \%)$ and $\mathrm{UR}_{S}(84.7 \%)$ are similar to those obtained from linear analysis. Eigenvalue buckling analysis was used to compute the buckling amplification factor $\alpha_{c r}$ (the factor with which the actions should be increased for global buckling to occur), which was 1.41

460 at its lowest. Hence, the optimized design is also considered safe after a more in-depth analysis.

\subsection{Discussion}

In all optimized designs, the structural material is mainly used in the tie rods (G1), the Vierendeel girders (G9 \& G12) and the rafters (G6) to provide sufficient stiffness in the transverse direction. The largest absolute weight savings occur in the ridge and gutter beams (G13, about 18 tons), followed by the infill of the front façades (G4, about 10 tons) and the main part of the Vierendeel girders (G9, about 9 tons). In contrast, structural material is added to the tie rods (G1, about 9 tons). For the members of the rafters (G6 \& G8), the outer chord of the central Vierendeel girders (G7) and the chords of the upper Vierendeel girders (G12), the cross-sectional dimensions are at their limit, and the same profiles are used as in the original design. For the other member groups (G2, G3, G5, G10 \& G11), less important material savings of 1 to 2 tons are obtained.

From the results it is apparent that the optimizer removes structural material where it is not needed and adds material where it is needed more. A significant portion of the material in the Market Hall primarily contributes to the stiffness 
of the structure. The optimized design is less stiff than the original design in the longitudinal $(\mathrm{Z})$ direction, where the displacements are far below the admissible ues, but it is more stiff in the transverse $(\mathrm{X})$ direction where the displacements are decisive. The highest $\mathrm{UR}_{R}$ values are found in the vertical and diagonal members near the supports (which absorb the shear forces of the main span) and in the members of the trimmer constructions. However, the Vierendeel girders and especially the ridge and gutter beams in the optimized design are used to a much larger fraction of their capacity, whereas the resistance of the tie rods is less critical. The highest $\mathrm{UR}_{S}$ values are found in the inner Vierendeel chord, the vertical members and the rafters near the supports, especially those on the inside of the roof. When compared to the original design, the ridge beams (which are mainly loaded in compression) are used to a larger fraction of their capacity in the optimized design, as are the light infill beams in the front façades. For both the resistance and the stability checks, the average member utilization ratio in the optimized design is higher.

The optimized design has been presented to the engineers from BAS to form the basis for a discussion, in which the value of structural optimization in the design process has been confirmed. The importance of keeping the number of member groups limited has been emphasized, so that steel members can be ordered in bulk, connection details can be reused, and finishing materials can be attached more easily. The engineer's experience and intuition are key when defining the groups of the members. Finally, additional design freedom would be possible if the GA could also control the type of the cross-section (HE or SHS).

The weight of a structure alone is not a comprehensive measure of the total cost. However, by grouping the members of the Market Hall in the optimized design in the same way as in the original design, it can be assumed that the associated costs (related to e.g. production and assembly) remain virtually unchanged, as the complexity of the design does not increase. As a result, the contribution of these associated costs to the total cost is factored out of the objective function.

The optimization runs in this article have been performed in parallel on a compute node with 36 cores (Intel Skylake, $2.3 \mathrm{GHz}, 192 \mathrm{~GB}$ RAM), where each run was aborted after two hours. On a personal laptop (Intel i7-7500U, $2.9 \mathrm{GHz}, 16 \mathrm{~GB}$ RAM) it takes about 12 hours to evaluate 1500 generations, which is typically sufficient for the GA to converge. The optimization process can therefore take place overnight, using standard infrastructure available to engineering offices, so that the designing engineers can proceed with the results in the next morning.

From the previous paragraphs, it is concluded that the GA is able to find satisfactory solutions to the problem at hand. The optimization strategy makes it possible to include Eurocode constraints as well as other practical and architectural requirements, by adding additional constraints or by making adjustments to the design space. With current weight savings of $15 \%$, further savings can be made by careful regrouping of members - either based on technical insight or on the results of previous optimizations - or by making the classifications of cross- 
sections dependent on the actions in the individual members. Furthermore, as 525 mostly the displacements in the transverse direction are decisive, additional savings can be made in this case by renegotiating the corresponding limit values or by using a combination of actions in SLS that is less conservative than the characteristic combination in equation (2). However, these interventions fall outside the scope of this article.

\section{Conclusions}

This article aims to investigate the feasibility and the potential of structural optimization methods in a realistic building context. The presented work is motivated by the absence of formal optimization methods in structural design practice, despite promising examples in the academic literature. Following from the observation that most test problems in academic literature are not representative of reality, this study considers the optimization of a realistic test case. The cross-sections of the members in the roof of the Ghent Market Hall are optimized, taking into account all relevant Eurocode constraints and technical requirements, thus simulating a realistic design situation. The MATLAB source code for the analysis of the Market Hall has been made available as supplementary material to serve as a new benchmark problem for the community.

Metaheuristic optimization algorithms are easy to use and to interpret, making them attractive for use in a practical context. In this study, the Genetic Algorithm that is built into MATLAB is applied to the sizing problem of the structural members, based on a commercial profile catalog. The original grouping of the members is preserved, so that (1) the optimized design is not more complicated than the original design and (2) the number of design variables is small enough for the Genetic Algorithm to find good solutions. An optimized design is obtained that uses $15 \%$ less steel than the original design, while still meeting all relevant constraints. These material savings would lead to equivalent reductions in terms of material costs and embodied carbon emissions. At the same time, the time-consuming process of sizing the structural members is automated, resulting in more efficient structures with less engineering effort.

Discussions with the structural designers of the Market Hall have confirmed the interest in the use of structural optimization for practical applications. However, there is a need for user-friendly optimization tools that respond to the design process. A more problem-oriented approach would help the academic community to bridge the gap between theory and practice, by promoting greater interaction with practicing engineers. From a practical point of view, there is a

560 need for fast(er) structural analysis software as well as easy ways to communicate with optimization software, either by using an API or by integrating them both in the same working environment. As a final note, it is emphasized that the approach should not be limited to steel alone: the embodied carbon values for concrete frames are comparable to those for steel [6], suggesting similar savings 565 for other building materials. 


\section{Acknowledgements}

This work has been performed in the frame of project C24/15/012 funded by the Industrial Research Fund of KU Leuven. The financial support is gratefully acknowledged. We would also like to thank S. Arnout from BAS for the insightful discussions, and D. Elleboog from BuildSoft support for providing details on the implementation of Eurocode 3 in Diamonds.

\section{A. Structural member groups}

The structural member groups are shown in figure A.13. They are identical to the member groups in the original design. Each member group is controlled by a single design variable. The available steel sections are listed in table A.4.

\section{B. Details on the Eurocode checks}

This appendix provides further details on the implementation of the Eurocode checks in section 4.

\section{B.1. Section properties}

The conventions and dimensions of the cross-sections used in this article are shown in figure B.14. The expressions for the shear area $A_{v}$ and the section modulus for St. Venant torsion $T_{e l, t}$ can be found below. The other section properties can be found in the section catalog or in the corresponding product standard. For SHS sections, the outer radius $r_{o}$ is calculated as 1.5 times the inner radius $r_{i}$, which in turn is equal to the wall thickness $t$. The 'strong' axis always refers to the $\mathrm{y}-\mathrm{y}$ axis, and the 'weak' axis refers to the $\mathrm{z}-\mathrm{z}$ axis.

\section{B.1.1. Shear area}

The shear area for HE sections with a load acting parallel to the web is [EC3: $\S 6.2 .6(3)]$ :

$$
A_{v, z}=A-2 b t_{f}+\left(t_{w}+2 r_{i}\right) t_{f} \geq \eta t_{w} h_{w}
$$

with $\eta$ conservatively taken equal to 1 . For loads parallel to the flanges, no expression is given in EC3. Diamonds uses the following formula:

$$
A_{v, y}=2 b t_{f}+t_{w}+r_{i} t_{w}
$$

For SHS sections, the shear area is:

$$
A_{v, y}=A_{v, z}=A \frac{h}{b+h}
$$




\section{B.1.2. Section modulus for St. Venant torsion}

The section modulus $T_{e l, t}$ for St. Venant torsion is computed as:

$$
T_{e l, t}=1.3 \frac{\left(2 b t_{f}^{3}\right)+\left(h-2 t_{f}\right) t_{w}^{3}}{3 a_{m}}
$$

for HE sections, with $a_{m}=\max \left(t_{f}, t_{w}\right)$, and as:

$$
T_{e l, t}=2(h-t)^{2} t
$$

for SHS sections.

\section{B.2. Reduced bending resistance [EC3: \$6.2.8 to §6.2.9]}

Both the axial force and the shear force may negatively affect the bending resistance of the cross-section. The effect of the shear force on the bending resistance is taken into account using the following formulae [EC3: Eq. 6.29]:

$$
\begin{aligned}
& M_{V, y, R d}=W_{y}\left(1-\rho_{z}\right) f_{y d} \\
& M_{V, z, R d}=W_{z}\left(1-\rho_{y}\right) f_{y d}
\end{aligned}
$$

where $W_{i}=W_{p l, i}$ for Class 1 and 2 cross-sections, $W_{e l, i}$ for Class 3 cross-sections and $W_{e f f, i}$ for Class 4 cross-sections. However, for Class 1 and 2 HE sections, equation (B.6) is replaced by [EC3: Eq. 6.30]:

$$
M_{V, y, R d}=\left(W_{p l, y}-\rho_{z} \frac{A_{w}^{2}}{4 t_{w}}\right) f_{y d}
$$

with $t_{w}$ the web thickness and $A_{w}=t_{w} h_{w}$ the web area. In these expressions, $\rho_{i}$ are reduction factor for shear. For uni-axial bending, the reduction factors $\rho_{i}$ are obtained using the following formula [EC3: $\left.\S 6.2 .8(3)\right]$ :

$$
\rho_{i}=\left(2 \frac{V_{i, E d}}{V_{p l, i, R d}}-1\right)^{2}
$$

but with $\rho_{i}=0$ if $\frac{V_{i, E d}}{V_{p l, i, R d}} \leq 0.5$. For bi-axial bending, the reduction factors $\rho_{i}$ in equations (B.8) to (B.7) are replaced by:

$$
\rho_{y z}=\left(2 \sqrt{\left(\frac{V_{y, E d}}{V_{p l, y, R d}}\right)^{2}+\left(\frac{V_{z, E d}}{V_{p l, z, R d}}\right)^{2}}-1\right)^{2}
$$

with $\rho_{y z}=0$ if $\sqrt{\left(\frac{V_{y, E d}}{V_{p l, y, R d}}\right)^{2}+\left(\frac{V_{z, E d}}{V_{p l, z, R d}}\right)^{2}} \leq 0.5$. In the case of Class 1 or 2 cross-sections, the effect of the axial force is taken into account via an additional reduction factor on the bending resistance. For SHS sections, this gives [EC3: Eqs. $6.39 \& 6.40]$ :

$$
M_{N V, i, R d}=M_{V, i, R d} \times \min \left\{\frac{1-n}{1-0.5 a}, 1\right\}
$$


for bending about either axis, where $n=N_{E d} / N_{p l, R d}$ and $a=\min \{1-$ $\left.2 b t_{f} / A, 0.5\right\}$. For HE sections, equation (B.11) has to be used for bending about the strong axis, while the expression for bending about the weak axis is [EC3: Eqs. 6.37 \& 6.38]:

$$
M_{N V, z, R d}=\left\{\begin{array}{l}
M_{V, z, R d} \text { for } n \leq a \\
M_{V, z, R d}\left(1-\left(\frac{n-a}{1-a}\right)^{2}\right) \text { for } n>a .
\end{array}\right.
$$

Finally, the interaction formula in equation (8) contains two coefficients $\alpha$ and $\beta$, which are as follows:

$$
\alpha=2 ; \quad \beta=\max (5 n, 1)
$$

for HE sections and as follows:

$$
\alpha=\beta=\min \left(\frac{1.66}{1-1.13 n^{2}}, 6\right)
$$

for SHS sections.

\section{B.3. Flexural buckling [EC3: \$6.3.1]}

Flexural buckling may occur in structural members that are loaded in compression. In order to take the effect of flexural buckling into account, the design compression resistance of a cross-section has to be multiplied by a reduction factor $\chi_{i}(i=y, z)$, which is different for buckling about the strong and weak axis:

$$
\chi_{i}=\frac{1}{\Phi_{i}+\sqrt{\Phi_{i}^{2}-\lambda_{i}^{2}}} \leq 1,
$$

with $\Phi_{i}=0.5\left(1+\alpha_{i}\left(\lambda_{i}-0.2\right)+\lambda_{i}^{2}\right), \lambda_{i}$ the non-dimensional slenderness of the member, and $\alpha_{i}$ the imperfection factor for the relevant buckling mode. For Class 1, 2 and 3 cross-sections, the non-dimensional slenderness is computed as:

$$
\lambda_{i}=\sqrt{\frac{A f_{y d}}{N_{c r, i}}},
$$

where the critical elastic force for flexural buckling $N_{c r, i}$ is obtained from equation (15). The imperfection factor $\alpha_{i}$ is to be determined from [EC3: Tables $6.1 \& 6.2]$, depending on the section properties and the steel grade. Buckling effects may be ignored when $\lambda_{i} \leq 0.2$.

\section{B.4. Torsional buckling [EC3: \$6.3.1.4]}

Torsional buckling may occur in members with open, doubly symmetric cross-sections that are loaded in compression. The reduction factor for torsional buckling $\chi_{T}$ is calculated in the same way as the reduction factor for flexural 
buckling, using the imperfection factor for buckling about the weak axis. The non-dimensional slenderness

$$
\lambda_{T}=\sqrt{\frac{A f_{y d}}{N_{c r, T}}}
$$

is based on the elastic torsional buckling force $N_{c r, T}$, which is obtained from equation (16).

\section{B.5. Lateral-torsional buckling [EC3: §6.3.2]}

Lateral-torsional buckling is a buckling mode that may occur when the bending moment $M_{y, E d}$ about the strong axis exceeds a certain critical value. Lateral-torsional buckling can only occur in members that are susceptible to torsional deformations. Of all cross-sections covered in this article, only HEtype sections can be susceptible to torsional deformations, which happens when both $I_{T}<I_{y}$ and

$$
\lambda_{0}>0.2 \sqrt{C_{1}} \sqrt[4]{\left(1-\frac{N_{E d}}{N_{c r, z}}\right)\left(1-\frac{N_{E d}}{N_{c r, T}}\right)},
$$

with $I_{T}$ the St. Venant torsional constant, $\lambda_{0}$ the non-dimensional slenderness for lateral-torsional buckling due to a uniform bending moment, and $C_{1}$ the equivalent uniform moment factor from equation (19) [EC3: Annex A]. The slenderness $\lambda_{0}$ is computed as

$$
\lambda_{0}=\sqrt{\frac{W_{y} f_{y d}}{M_{c r, 0}}}
$$

with $W_{y}$ the section modulus for the relevant cross-section class, $f_{y d}$ the design yield strength, and $M_{c r, 0}$ the elastic critical moment for a uniform bending moment, obtained by taking $C_{1}$ equal to 1 in equation (18).

For members that are susceptible to torsional deformations, the reduction factor for torsional buckling $\chi_{L T}$ is calculated in a similar way as in the previous sections:

$$
\chi_{L T}=\frac{1}{\Phi_{L T}+\sqrt{\Phi_{L T}^{2}-\lambda_{L T}^{2}}} \leq 1
$$

with $\Phi_{L T}=0.5\left(1+\alpha_{L T}\left(\lambda_{L T}-0.2\right)+\lambda_{L T}^{2}\right)$, following the general method in [EC3: $§ 6.3 .2 .2]$. The imperfection factor $\alpha_{L T}$ is determined from [EC3: Tables $6.3 \& 6.4]$ based on the type of the cross-section. The slenderness $\lambda_{L T}$ is based on the resistance to bending about the strong axis:

$$
\lambda_{L T}=\sqrt{\frac{W_{y} f_{y d}}{M_{c r}}},
$$


where $W_{y}$ is the plastic section modulus $W_{p l, y}$ for Class 1 and 2 cross-sections, the elastic section modulus $W_{e l, y}$ for Class 3 cross-sections and the effective section modulus $W_{e f f, y}$ for Class 4 cross-sections. Lateral-torsional buckling effects are ignored when $\lambda_{L T} \leq 0.2$, based on [EC3: Figure 6.4]. For members that are not susceptible to torsional deformations, no lateral-torsional buckling check is required, and $\chi_{L T}=1$.

\section{B.6. Interaction effects [EC3: $§ 6.3 .3]$}

The following paragraphs provide additional information to the interaction formulas for in- and out-of-plane buckling in equations (20) and (21). First, auxiliary factors $C_{m}$ for equivalent moment and $C_{i j}$ for plastic behaviour are determined, which are then used to compute the interaction factors $k_{i j}$. The procedures may vary depending on the class of the cross-section and the sensitivity of the member to torsional deformations.

\section{B.6.1. Equivalent moment factors $C_{m}$}

The factors $C_{m}$ are the equivalent moment factors. They are initially computed for a uniform bending moment, after which they are updated to match the actual moment distribution. The equivalent uniform moment factors are:

$$
C_{m i, 0}=1+\left(\frac{\pi^{2} E I_{i}|w|}{L^{2}\left|M_{i, E d}\right|}-1\right) \frac{N_{E d}}{N_{c r, i}},
$$

for the general case, and

$$
C_{m i, 0}=0.79+0.21 \psi_{i}+0.36\left(\psi_{i}-0.33\right) \frac{N_{E d}}{N_{c r, i}}
$$

for the case where the maximum moment occurs at one of the member ends, where $|w|$ is the maximum lateral deflection of the member, $\left|M_{i, E d}\right|$ is the maximum first-order bending moment, $N_{E d}$ is the design value of the compression force, $N_{c r, i}$ is the critical elastic force, and $-1 \leq \psi_{i} \leq 1$ is the end moment ratio. To avoid numerical issues, it is imposed that $N_{E d} / N_{c r, i} \leq 0.99$. In a following step, the uniform moment factors $C_{m i, 0}$ are updated according to the actual (second-order) bending moment distribution along the member, taking into account the effect of the compression force and the shape of the cross-section:

$$
\begin{aligned}
& C_{m y}=C_{m y, 0}+\left(1-C_{m y, 0}\right) \frac{\sqrt{\epsilon_{y}} a_{L T}}{1+\sqrt{\epsilon_{y}} a_{L T}} \\
& C_{m z}=C_{m z, 0} \\
& C_{m L T}=\frac{C_{m y}^{2} a_{L T}}{\sqrt{\left(1-\frac{N_{E d}}{N_{c r, z}}\right)\left(1-\frac{N_{E d}}{N_{c r, T}}\right)}} \geq 1,
\end{aligned}
$$

where

$$
\epsilon_{y}=\frac{M_{y, E d}}{N_{E d}} \frac{A}{W_{e l, y}}
$$


for Class 1, 2 and 3 cross-sections and

$$
\epsilon_{y}=\frac{M_{y, E d}}{N_{E d}} \frac{A_{e f f}}{W_{e f f, y}}
$$

for Class 4 cross-sections and where $a_{L T}$ is a factor that represents the transition between open and closed cross-sections:

$$
a_{L T}=1-\frac{I_{T}}{I_{y}} \geq 0 .
$$

In case of members not susceptible to torsional deformations, $a_{L T}=0$, and so $C_{m y}=C_{m y, 0}, C_{m z}=C_{m z, 0}$ and $C_{m L T}=1$. The expressions above apply to

Class 1, 2, 3 and 4 cross-sections alike.

\section{B.6.2. Factors $C_{i j}$ for plastic behaviour}

The factors $C_{y y}, C_{z z}, C_{y z}$ and $C_{z y}$ are auxiliary factors that represent the amount of plastic behaviour in the cross-section at the time of collapse. For members with Class 1 and 2 cross-sections that are susceptible to torsional deformations, these are:

$$
\begin{aligned}
& C_{y y}=1+\left(w_{y}-1\right)\left[\left(2-\left(1+\lambda_{\max }\right)\left(\frac{1.6}{w_{y}} C_{m y}^{2} \lambda_{\max }\right)\right) n_{p l}-b_{L T}\right] \geq \frac{W_{e l, y}}{W_{p l, y}} \\
& C_{y z}=1+\left(w_{z}-1\right)\left[\left(2-14 \frac{C_{m z}^{2} \lambda_{\max }^{2}}{w_{z}^{5}}\right) n_{p l}-c_{L T}\right] \geq 0.6 \sqrt{\frac{w_{z}}{w_{y}}} \frac{W_{e l, z}}{W_{p l, z}} \\
& C_{z y}=1+\left(w_{y}-1\right)\left[\left(2-14 \frac{C_{m y}^{2} \lambda_{\max }^{2}}{w_{y}^{5}}\right) n_{p l}-d_{L T}\right] \geq 0.6 \sqrt{\frac{w_{y}}{w_{z}}} \frac{W_{e l, y}}{W_{p l, y}} \\
& C_{z z}=1+\left(w_{z}-1\right)\left[2-\left(1+\lambda_{\max }\right)\left(\frac{1.6}{w_{z}} C_{m z}^{2} \lambda_{\max }\right)-e_{L T}\right] n_{p l} \geq \frac{W_{e l, z}}{W_{p l, z}}
\end{aligned}
$$

with $w_{i}=W_{p l, i} / W_{e l, i} \leq 1.5, \lambda_{\max }=\max \left(\lambda_{y}, \lambda_{z}\right), n_{p l}=\gamma_{M 1} N_{E d} / N_{R k}$ and

$$
\begin{aligned}
b_{L T} & =0.5 a_{L T} \lambda_{0}^{2} \frac{M_{y, E d}}{\chi_{L T} M_{p l, y, R d}} \frac{M_{z, E d}}{M_{p l, z, R d}} \\
c_{L T} & =10 a_{L T} \frac{\lambda_{0}^{2}}{5+\lambda_{z}^{4}} \frac{M_{y, E d}}{C_{m y} \chi_{L T} M_{p l, y, R d}} \\
d_{L T} & =2 a_{L T} \frac{\lambda_{0}}{0.1+\lambda_{z}^{4}} \frac{M_{y, E d}}{C_{m y} \chi_{L T} M_{p l, y, R d}} \frac{M_{z, E d}}{C_{m z} M_{p l, z, R d}} \\
e_{L T} & =1.7 a_{L T} \frac{\lambda_{0}}{0.1+\lambda_{z}^{4}} \frac{M_{y, E d}}{C_{m y} \chi_{L T} M_{p l, y, R d}},
\end{aligned}
$$

where $a_{L T}$ is the same as in equation (B.29). For members that are not susceptible to torsional deformations, $a_{L T}=0$, and so $b_{L T}=c_{L T}=d_{L T}=e_{L T}=0$ 
as well. For members with cross-sections of Class 3 and above, the factors for plastic behaviour are simply:

$$
\begin{aligned}
C_{y y} & =C_{z z}=1 \\
C_{y z} & =C_{z y}=0.6
\end{aligned}
$$

regardless of the effects of torsional deformations.

\section{B.6.3. Interaction factors $k_{i j}$}

From the auxiliary factors, the interaction factors $k_{y y}, k_{z z}, k_{y z}$ and $k_{z y}$ are determined on the basis of Table A.1 of [EC3: Annex A]. First, an additional auxiliary variable is defined:

$$
\mu_{i}=\frac{1-\frac{N_{E d}}{N_{c r, i}}}{1-\chi_{i} \frac{N_{E d}}{N_{c r, i}}}
$$

with $N_{E d}$ the design value of the compression force, $N_{c r, i}$ the elastic critical force, and $\chi_{i}$ the reduction factor for flexural buckling $(i=y, z)$. Next, the interaction factors are computed as follows:

$$
\begin{aligned}
& k_{y y}=C_{m y} C_{m L T} \mu_{y}\left(1-\frac{N_{E d}}{N_{c r, y}}\right)^{-1} \frac{1}{C_{y y}} \\
& k_{y z}=C_{m z} \mu_{y}\left(1-\frac{N_{E d}}{N_{c r, z}}\right)^{-1} \frac{0.6}{C_{y z}} \sqrt{\frac{w_{z}}{w_{y}}} \\
& k_{z y}=C_{m y} C_{m L T} \mu_{z}\left(1-\frac{N_{E d}}{N_{c r, y}}\right)^{-1} \frac{0.6}{C_{z y}} \sqrt{\frac{w_{y}}{w_{z}}} \\
& k_{z z}=C_{m z} \mu_{z}\left(1-\frac{N_{E d}}{N_{c r, z}}\right)^{-1} \frac{1}{C_{z z}}
\end{aligned}
$$

with $w_{i}$ as in section B.6.2 for Class 1 and 2 cross-sections and $w_{i}=1$ for Class 3 and 4 cross-sections.

\section{References}

[1] F. Pomponi, A. Moncaster, Reducing embodied carbon in the built environment: A research agenda, in: International Conference on Sustainable Ecological Engineering Design for Society, Leeds, UK, 2016.

${ }_{630}[2]$ R. Crawford, Life Cycle Assessment in the Built Environment, Spon Press, London, New York, 2011.

[3] T. Ibn-Mohammed, R. Greenough, S. Taylor, L. Ozawa-Meida, A. Acquaye, Operational vs. embodied emissions in buildings - a review of current trends, Energy and Buildings 66 (2013) 232-245. 
[4] M. Webster, H. Meryman, A. Slivers, T. Rodriguez-Nikl, L. Lemay, K. Simonen, Structure and carbon - how materials affect the climate, SEI Sustainability Committee, Carbon Working Group, ASCE (2012).

[5] C. Thirion, Putting the material in the right place: Investigations into the sustainable use of structural materials to reduce the initial embodied environmental impact of building structures, Ph.D. thesis, UCL (University College London) (2013).

[6] S. Kaethner, J. Burridge, Embodied CO2 of structural frames, The Structural Engineer 90 (5) (2012) 33-40.

[7] J. Allwood, J. Cullen, M. Carruth, D. Cooper, M. McBrien, R. Milford, M. Moynihan, A. Patel, Sustainable materials: with both eyes open, Cambridge, UK: UIT Cambridge Limited, 2012.

[8] J. Orr, A. Bras, T. Ibell, Effectiveness of design codes for life cycle energy optimisation, Energy and Buildings 140 (2017) 61-67.

[9] IEA, Energy technology transitions for industry. Paris: International Energy Agency, available from: www.iea.org (2009).

[10] J. Allwood, M. Ashby, T. Gutowski, E. Worrell, Material efficiency: A white paper, Resources, Conservation and Recycling 55 (3) (2011) 362381.

[11] M. Carruth, J. Allwood, M. Moynihan, The technical potential for reducing metal requirements through lightweight product design, Resources, Conservation and Recycling 57 (2011) 48-60.

[12] Greenhouse gas emissions: structural design codes overlooked, Press release (2018).

[13] F. Needham, The economics of steelwork design, The Structural Engineer 55 (9) (1977) 367-373.

[14] C. Gibbons, Economic steelwork design, The Structural Engineer 73 (15) (1995) 250-253.

[15] M. Moynihan, J. Allwood, Utilization of structural steel in buildings, Proceedings of The Royal Society A 470 (2168) (2014) 20140170.

665 [16] A. Templeman, Optimization methods in structural design practice, Journal of Structural Engineering 109 (10) (1983) 2420-2433.

[17] M. Cohn, A. Dinovitzer, Application of structural optimization, Journal of Structural Engineering 120 (2) (1994) 617-650.

[18] M. Stolpe, Truss optimization with discrete design variables: a critical review, Structural and Multidisciplinary Optimization 53 (2) (2016) 349374 . 
[19] A. Furuto, Market Hall in Ghent / Marie-José Van Hee + Robbrecht \& Daem, by Hufton + Crow, ArchDaily. Published online, accessed 10 Oct 2019. https://www.archdaily.com/368920/ market-hall-in-ghent-marie-jose-van-hee-robbrecht-and-daem-by-hufton-crow/ ISSN 0719-8884 (May 2013).

[20] J. Arora, M. Huang, Discrete structural optimization with commercially available sections, Structural Engineering/Earthquake Engineering 13 (2) (1996) 105-122.

[21] J. Nocedal, S. Wright, Numerical optimization, Springer Science \& Business Media, 2006.

[22] S. Mehrotra, On the implementation of a primal-dual interior point method, SIAM Journal on Optimization 2 (4) (1992) 575-601.

[23] D. Sorensen, Newton's method with a model trust region modification, SIAM Journal on Numerical Analysis 19 (2) (1982) 409-426.

[24] C. Fleury, CONLIN: an efficient dual optimizer based on convex approximation concepts, Structural Optimization 1 (2) (1989) 81-89.

[25] K. Svanberg, The method of moving asymptotes - a new method for structural optimization, International Journal for Numerical Methods in Engineering 24 (2) (1987) 359-373.

[26] U. Ringertz, On methods for discrete structural optimization, Engineering Optimization 13 (1) (1988) 47-64.

[27] F. Flager, G. Soremekun, A. Adya, K. Shea, J. Haymaker, M. Fischer, Fully constrained design: A general and scalable method for discrete member sizing optimization of steel truss structures, Computers \& Structures 140 (2014) 55-65.

[28] M. Schevenels, S. McGinn, A. Rolvink, J. Coenders, An optimality criteria based method for discrete design optimization taking into account buildability constraints, Structural and Multidisciplinary Optimization 50 (5) (2014) 755-774.

[29] J. Holland, et al., Adaptation in natural and artificial systems: an introductory analysis with applications to biology, control, and artificial intelligence, MIT Press, 1992.

[30] J. Kennedy, R. Eberhart, Particle swarm optimization, in: Proceedings of the IEEE International Conference on Neural Networks, Vol. 4, Piscataway, NJ, US, 1995, pp. 1942-1948.

[31] S. Kirkpatrick, C. Gelatt Jr, M. Vecchi, Optimization by simulated annealing, Science 220 (4598) (1983) 671-680. 
[32] R. Bellman, Dynamic programming, Science 153 (3731) (1966) 34-37.

[33] S. Rajeev, C. Krishnamoorthy, Discrete optimization of structures using genetic algorithms, Journal of Structural Engineering 118 (5) (1992) 12331250 .

[34] S. Rajan, Sizing, shape, and topology design optimization of trusses using genetic algorithm, Journal of Structural Engineering 121 (10) (1995) 14801487.

[35] K. Sörensen, Metaheuristics - the metaphor exposed, International Transactions in Operational Research 22 (1) (2015) 3-18.

[36] C. Blum, A. Roli, Metaheuristics in combinatorial optimization: Overview and conceptual comparison, ACM Computing Surveys (CSUR) 35 (3) (2003) 268-308.

[37] J. Arora, Introduction to Optimum Design, 4th Edition, Academic Press, Boston, 2017.

[38] A. Kaveh, M. Ghazaan, Meta-heuristic algorithms for optimal design of real-size structures, Springer, 2018.

725 [39] A. Kaveh, K. Laknejadi, B. Alinejad, Performance-based multi-objective optimization of large steel structures, Acta Mechanica 223 (2) (2012) 355369.

[40] A. Kaveh, M. Kalateh-Ahani, M. Fahimi-Farzam, Damage-based optimization of large-scale steel structures, Earthquakes and Structures 7 (6) (2014) 1119-1139.

[41] A. Kaveh, A. BolandGerami, Optimal design of large-scale space steel frames using cascade enhanced colliding body optimization, Structural and Multidisciplinary Optimization 55 (1) (2017) 237-256.

[42] S. Gholizadeh, E. Salajegheh, Optimal seismic design of steel structures by an efficient soft computing based algorithm, Journal of Constructional Steel Research 66 (1) (2010) 85-95.

[43] G. Guerlement, R. Targowski, W. Gutkowski, J. Zawidzka, J. Zawidzki, Discrete minimum weight design of steel structures using EC3 code, Structural and Multidisciplinary Optimization 22 (4) (2001) 322-327.

740 [44] J. Jalkanen, Tubular truss optimization using heuristic algorithms, Ph.D. thesis, Tampere University of Technology (2007).

[45] K. Mela, Resolving issues with member buckling in truss topology optimization using a mixed variable approach, Structural and Multidisciplinary OptimizationPublished online (2014). 
[46] R. Van Mellaert, G. Lombaert, M. Schevenels, Global size optimization of statically determinate trusses considering displacement, member, and joint constraints, Journal of Structural Engineering 142 (2) (2016) 04015120.

[47] R. Van Mellaert, K. Mela, T. Tiainen, M. Heinisuo, G. Lombaert, M. Schevenels, Mixed-integer linear programming approach for global discrete sizing optimization of frame structures, Structural and Multidisciplinary Optimization 57 (2) (2018) 579-593.

[48] J. Brütting, J. Desruelle, G. Senatore, C. Fivet, Design of truss structures through reuse, in: Structures, Vol. 18, Elsevier, 2019, pp. 128-137.

[49] B. D'Amico, F. Pomponi, Accuracy and reliability: A computational tool to minimise steel mass and carbon emissions at early-stage structural design, Energy and Buildings 168 (2018) 236-250.

[50] R. Vierlinger, A. Hofmann, K. Bollinger, Emergent hybrid prefab structures in dwellings, in: Proceedings of the IASS Symposium, Wroclaw, Poland, 2013.

[51] J. Richardson, G. Nordenson, R. Laberenne, R. Coelho, S. Adriaenssens, Flexible optimum design of a bracing system for façade design using multiobjective genetic algorithms, Automation in Construction 32 (2013) 80-87.

[52] BuildSoft, Stadshal, Published online, accessed 10 Oct 2019. http://www. buildsoft.eu/nl/referentieproject/ (January 2019).

[53] O. Zienkiewicz, R. Taylor, P. Nithiarasu, J. Zhu, The finite element method, Vol. 3, McGraw-hill London, 1977.

[54] D. Dooms, et al., Stabil: A finite element toolbox for Matlab (2009).

[55] M. Serna, A. López, I. Puente, D. Yong, Equivalent uniform moment factors for lateral-torsional buckling of steel members, Journal of Constructional Steel Research 62 (6) (2006) 566-580. 


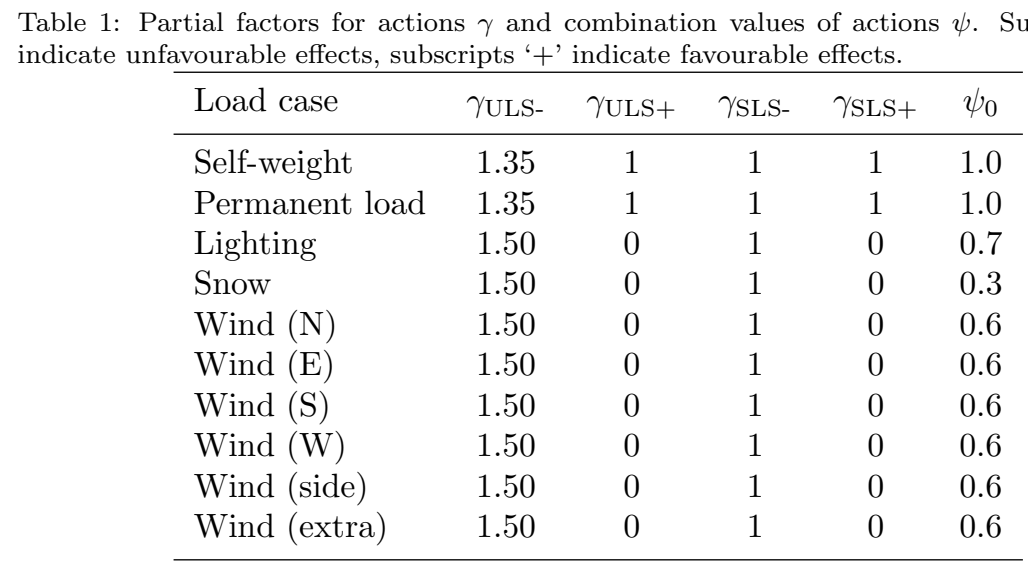

\begin{tabular}{|c|c|c|}
\hline $\begin{array}{l}\text { Member } \\
\text { group }\end{array}$ & $\begin{array}{l}\text { Original } \\
\text { design }\end{array}$ & $\begin{array}{l}\text { Optimized } \\
\text { design }\end{array}$ \\
\hline G1 & R 60 & R 75 \\
\hline G2 & HE $280 \mathrm{~A}$ & HE $140 \mathrm{M}$ \\
\hline G3 & HE $280 \mathrm{~A}$ & HE $240 \mathrm{~A}$ \\
\hline G4 & HE $280 \mathrm{~B}$ & HE $160 \mathrm{~A}$ \\
\hline G5 & HE $300 \mathrm{~B}$ & HE $280 \mathrm{~A}$ \\
\hline G6 & HE $300 \mathrm{~B}$ & HE $300 \mathrm{~B}$ \\
\hline G7 & HE $320 \mathrm{~B}$ & HE $320 \mathrm{~B}$ \\
\hline G8 & HE 360 B & HE $360 \mathrm{~B}$ \\
\hline G9 & SHS $300 \times 12.5$ & SHS $300 \times 10$ \\
\hline G10 & SHS $300 \times 16$ & SHS $300 \times 10$ \\
\hline G11 & SHS $350 \times 16$ & SHS $350 \times 14.2$ \\
\hline G12 & SHS $300 \times 16$ & SHS $300 × 16$ \\
\hline G13 & SHS $400 \times 20$ & SHS $350 \times 8$ \\
\hline
\end{tabular}




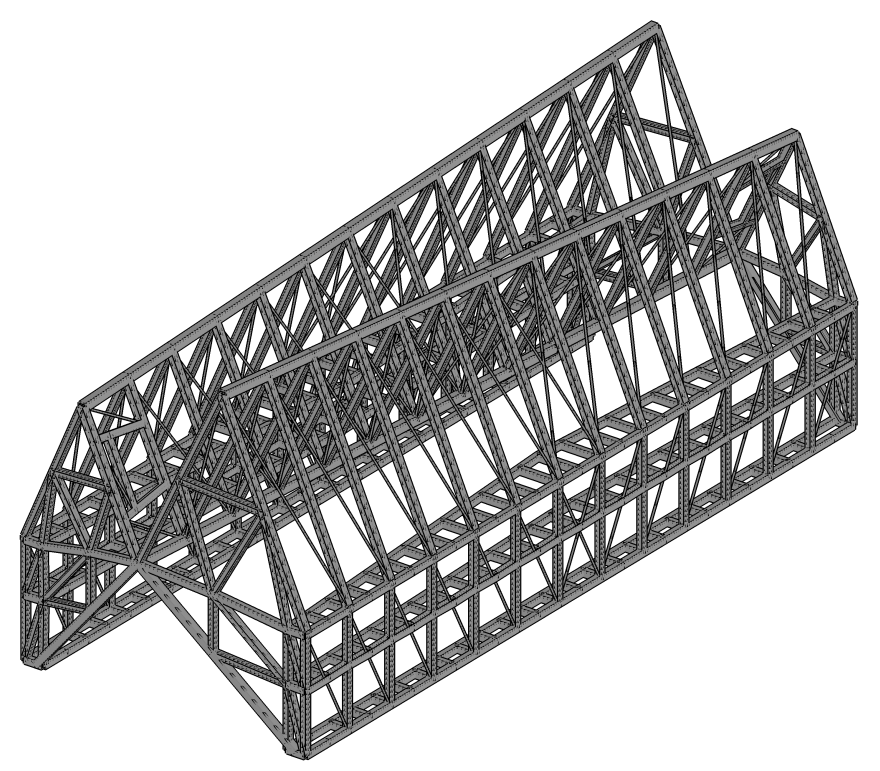

Figure 7: Original design: geometry (226.6 tons).

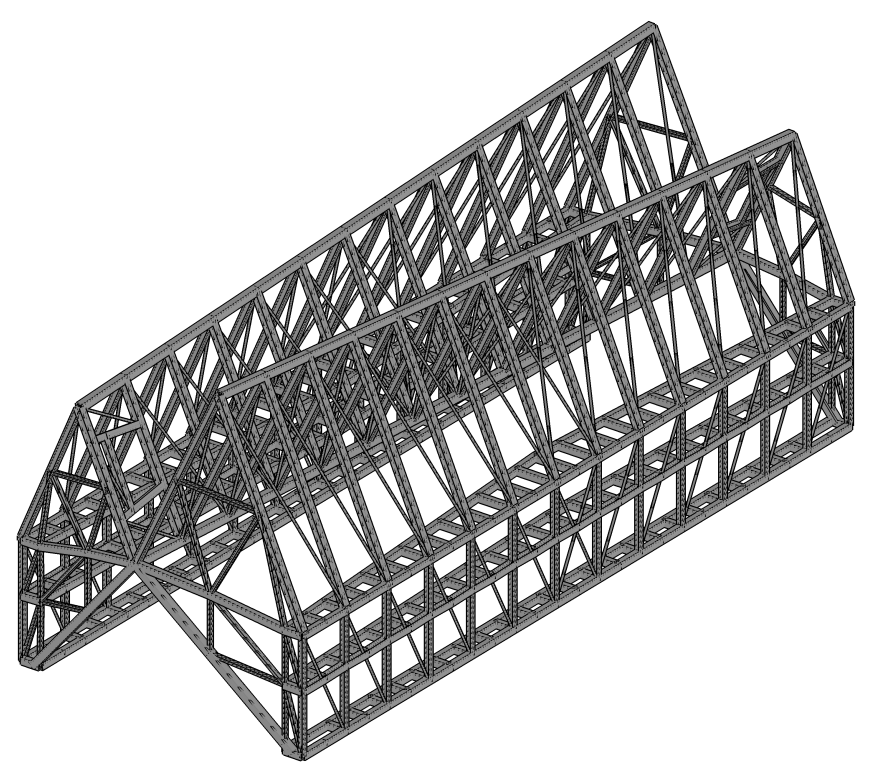

Figure 8: Optimized design: geometry (192.7 tons). 


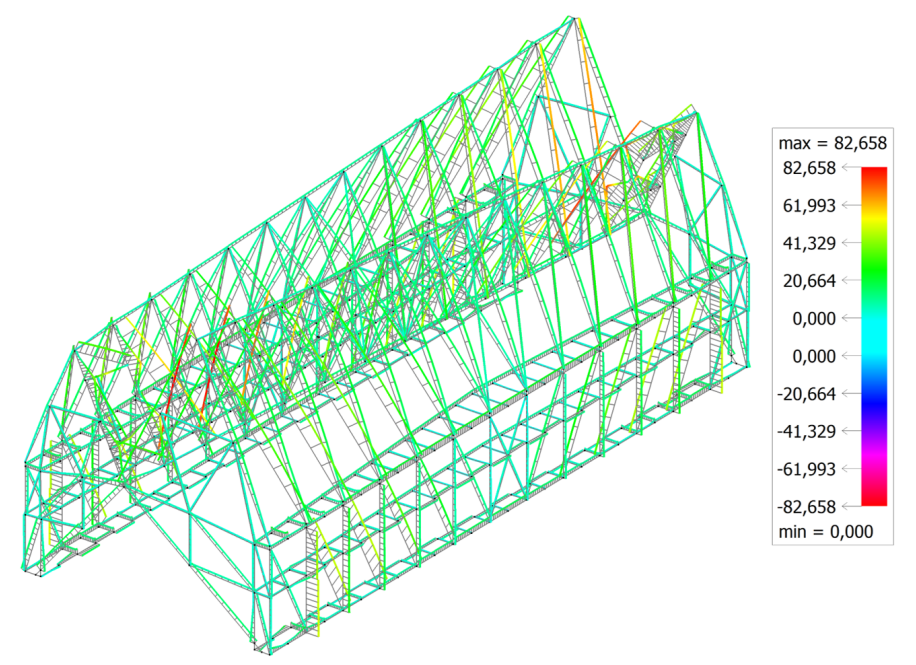

Figure 9: Original design: $\mathrm{UR}_{R}$ in Diamonds.

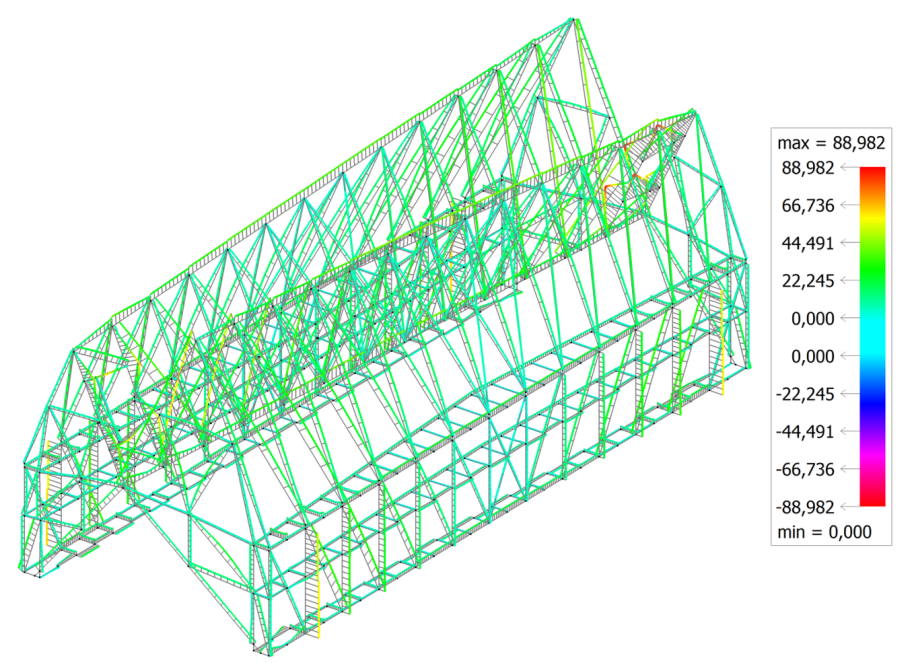

Figure 10: Optimized design: $\mathrm{UR}_{R}$ in Diamonds. 


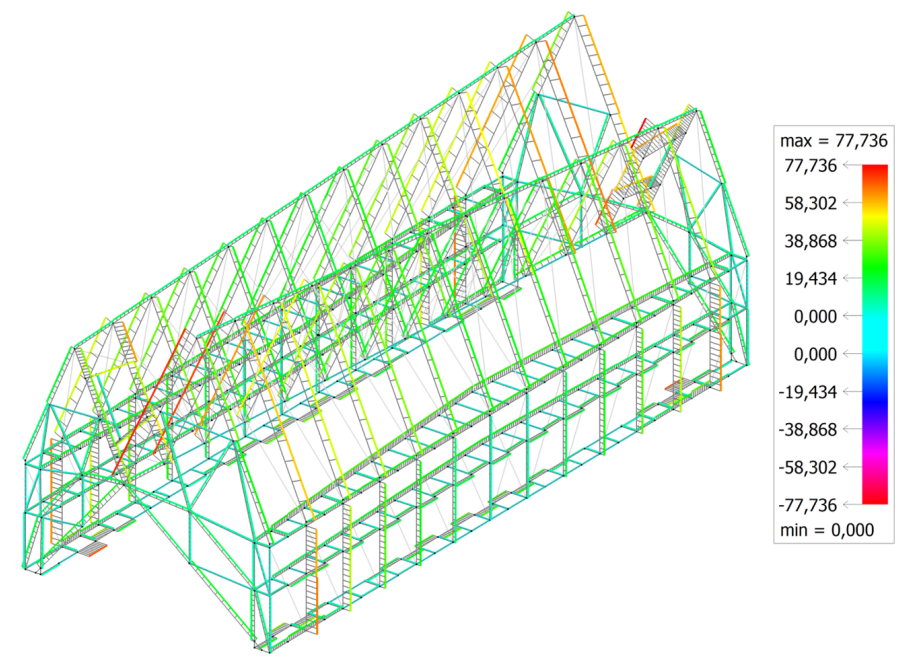

Figure 11: Original design: $\mathrm{UR}_{S}$ in Diamonds.

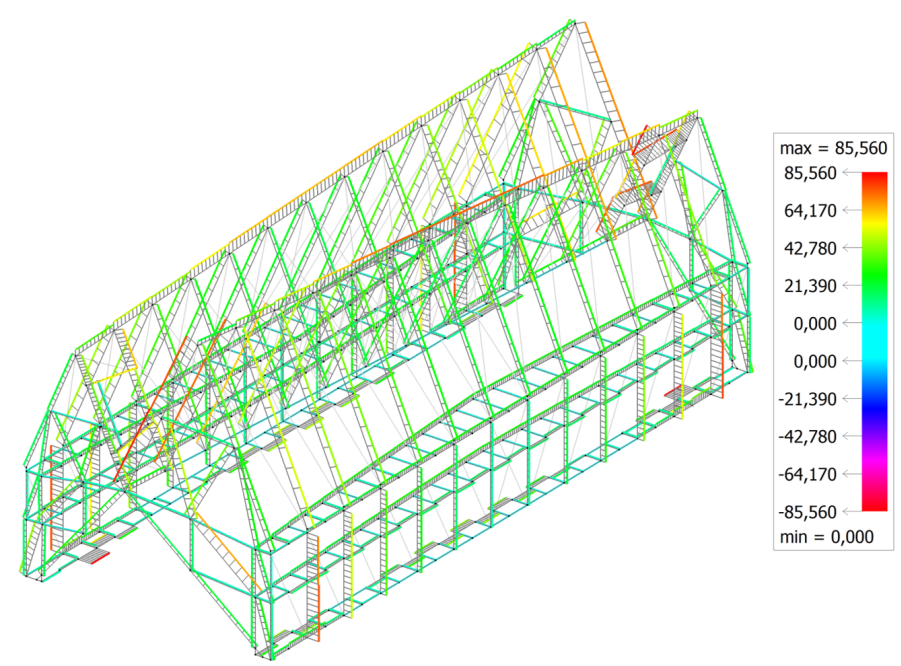

Figure 12: Optimized design: $\mathrm{UR}_{S}$ in Diamonds (no stability checks apply to the tie rods). 
Table 3: Global SLS displacement values in Diamonds (in $\mathrm{mm}$ ). Exclamation marks (!) are added next to the displacement values that exceed the limit value in nonlinear analysis. It is clear that the optimized design has more stiffness where the global displacement constraints are critical, and less stiffness where the displacement constraints are inactive.

\begin{tabular}{|c|c|c|c|c|c|c|}
\hline \multirow[t]{2}{*}{ Name } & \multirow[t]{2}{*}{ Description } & \multirow[t]{2}{*}{ Limit value } & \multicolumn{2}{|c|}{ Original design } & \multicolumn{2}{|c|}{ Optimized design } \\
\hline & & & linear & nonlinear & linear & nonlinear \\
\hline$\delta_{X, l i m, s b, v a r}$ & side walls bottom & 30.0 & 17.7 & 17.6 & 21.7 & 21.7 \\
\hline$\delta_{X, \text { lim }, \text { st }, \text { var }}$ & side walls top & 36.7 & 36.7 & $37.5(!)$ & 36.7 & $38.5(!)$ \\
\hline$\delta_{X, l i m, \text { rid,var }}$ & ridge beams & 50.2 & 43.0 & 43.5 & 37.4 & 38.8 \\
\hline$\delta_{X, l i m, \text { rid,tot }}$ & ridge beams & 63.3 & 63.3 & $63.8(!)$ & 59.4 & 60.8 \\
\hline$\delta_{X, l i m, g u t, v a r}$ & gutter beam & 50.2 & 50.2 & $50.6(!)$ & 42.9 & 43.5 \\
\hline$\delta_{X, l i m, g u t, t o t}$ & gutter beam & 63.3 & 50.6 & 50.6 & 42.9 & 43.5 \\
\hline$\delta_{Y, l i m, v a r}$ & mid-span & 30.0 & 9.9 & 9.9 & 9.5 & 9.6 \\
\hline$\delta_{Y, \text { lim }, \text { tot }}$ & mid-span & 110.5 & 50.5 & 50.4 & 48.5 & 48.5 \\
\hline$\delta_{Z, l i m, e n d, t o t}$ & front façades & 30.0 & 4.3 & 4.3 & 6.3 & 6.6 \\
\hline
\end{tabular}

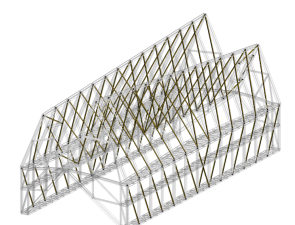

G1

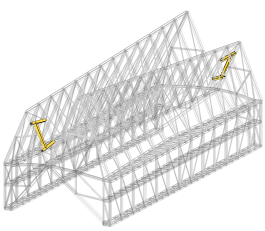

G5

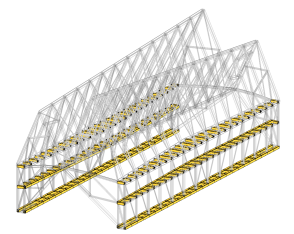

G9

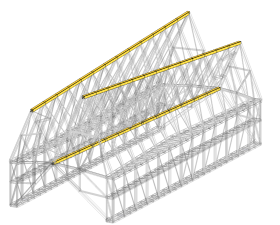

G13

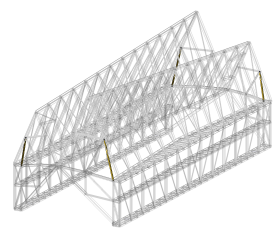

G2

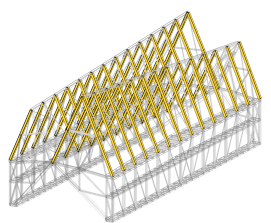

G6

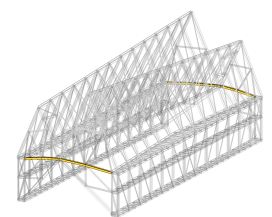

G10

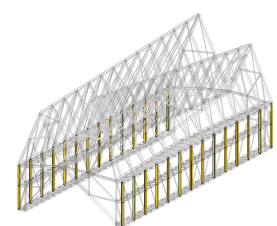

G3

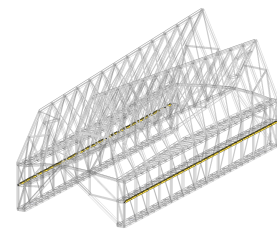

G7

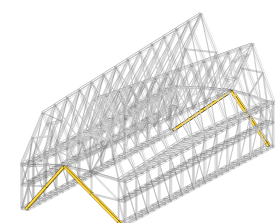

G11

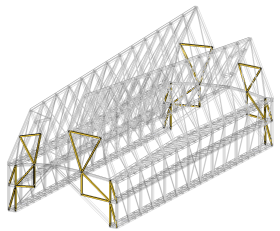

G4

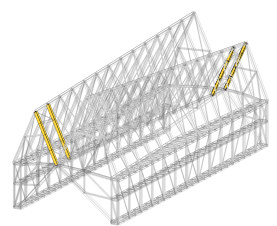

G8

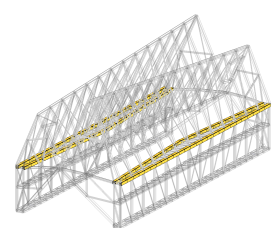

G12

Figure A.13: Structural member groups. 
Table A.4: The standardized steel sections that can be used in the optimization process.

\begin{tabular}{|c|c|c|c|c|c|c|c|c|c|c|c|}
\hline No. & Name & No. & Name & No. & Name & No. & Name & No. & Name & No. & Name \\
\hline 1 & R 30 & 26 & R 55 & 51 & SHS $180 \times 16$ & 76 & SHS $260 \times 16$ & 101 & $\mathrm{HE} 140 \mathrm{M}$ & 126 & HE $320 \mathrm{~A}$ \\
\hline 2 & R 31 & 27 & R 55.8 & 52 & SHS $200 \times 5$ & 77 & SHS $300 \times 6.3$ & 102 & $\mathrm{HE} 160 \mathrm{~A}$ & 127 & HE $320 \mathrm{~B}$ \\
\hline 3 & R 32 & 28 & R 56 & 53 & SHS $200 \times 6.3$ & 78 & SHS $300 \times 8$ & 103 & HE $160 \mathrm{~B}$ & 128 & HE $320 \mathrm{M}$ \\
\hline 4 & R 34 & 29 & R 57 & 54 & SHS $200 \times 8$ & 79 & SHS $300 \times 10$ & 104 & $\mathrm{HE} 160 \mathrm{M}$ & 129 & HE $340 \mathrm{~A}$ \\
\hline 5 & R 34.4 & 30 & R 58 & 55 & SHS $200 \times 10$ & 80 & SHS $300 \times 12.5$ & 105 & $\mathrm{HE} 180 \mathrm{~A}$ & 130 & HE $340 \mathrm{~B}$ \\
\hline 6 & R 35 & 31 & R 59 & 56 & SHS $200 \times 12.5$ & 81 & SHS $300 \times 14.2$ & 106 & $\mathrm{HE} 180 \mathrm{~B}$ & 131 & HE $340 \mathrm{M}$ \\
\hline 7 & R 35.7 & 32 & R 60 & 57 & SHS $200 \times 14.2$ & 82 & SHS $300 \times 16$ & 107 & $\mathrm{HE} 180 \mathrm{M}$ & 132 & HE $360 \mathrm{~A}$ \\
\hline 8 & R 36 & 33 & R 62 & 58 & SHS $200 \times 16$ & 83 & SHS $350 \times 8$ & 108 & $\mathrm{HE} 200 \mathrm{~A}$ & 133 & HE $360 \mathrm{~B}$ \\
\hline 9 & R 37 & 34 & R 63 & 59 & SHS $220 \times 6.3$ & 84 & SHS $350 \times 10$ & 109 & HE $200 \mathrm{~B}$ & 134 & HE $360 \mathrm{M}$ \\
\hline 10 & R 38 & 35 & R 65 & 60 & SHS $220 \times 8$ & 85 & SHS $350 \times 12.5$ & 110 & $\mathrm{HE} 200 \mathrm{M}$ & 135 & $\mathrm{HE} 400 \mathrm{~A}$ \\
\hline 11 & R 39 & 36 & R 70 & 61 & SHS $220 \times 10$ & 86 & SHS $350 \times 14.2$ & 111 & $\mathrm{HE} 220 \mathrm{~A}$ & 136 & HE $400 \mathrm{~B}$ \\
\hline 12 & R 39.2 & 37 & R 75 & 62 & SHS $220 \times 12.5$ & 87 & SHS $350 \times 16$ & 112 & $\mathrm{HE} 220 \mathrm{~B}$ & 137 & HE $400 \mathrm{M}$ \\
\hline 13 & R 40 & 38 & $\mathrm{R} 80$ & 63 & SHS $220 \times 14.2$ & 88 & SHS $400 \times 10$ & 113 & $\mathrm{HE} 220 \mathrm{M}$ & 138 & HE $450 \mathrm{~A}$ \\
\hline 14 & R 42 & 39 & $\mathrm{R} 85$ & 64 & SHS $220 \times 16$ & 89 & SHS $400 \times 12.5$ & 114 & $\mathrm{HE} 240 \mathrm{~A}$ & 139 & HE $450 \mathrm{~B}$ \\
\hline 15 & R 44 & 40 & $\mathrm{R} 90$ & 65 & SHS $250 \times 6.3$ & 90 & SHS $400 \times 14.2$ & 115 & $\mathrm{HE} 240 \mathrm{~B}$ & 140 & HE $450 \mathrm{M}$ \\
\hline 16 & $\mathrm{R} 45$ & 41 & R 95 & 66 & SHS $250 \times 8$ & 91 & SHS $400 \times 16$ & 116 & $\mathrm{HE} 240 \mathrm{M}$ & 141 & HE $500 \mathrm{~A}$ \\
\hline 17 & R 46 & 42 & R 100 & 67 & SHS $250 \times 10$ & 92 & SHS $400 \times 20$ & 117 & $\mathrm{HE} 260 \mathrm{~A}$ & 142 & HE $500 \mathrm{~B}$ \\
\hline 18 & R 47 & 43 & R 105 & 68 & SHS $250 \times 12.5$ & 93 & HE $100 \mathrm{~A}$ & 118 & $\mathrm{HE} 260 \mathrm{~B}$ & 143 & HE $500 \mathrm{M}$ \\
\hline 19 & R 48 & 44 & R 110 & 69 & SHS $250 \times 14.2$ & 94 & HE $100 \mathrm{~B}$ & 119 & HE $260 \mathrm{M}$ & 144 & HE $550 \mathrm{~A}$ \\
\hline 20 & R 49.2 & 45 & SHS $180 \times 5$ & 70 & SHS $250 \times 16$ & 95 & $\mathrm{HE} 100 \mathrm{M}$ & 120 & $\mathrm{HE} 280 \mathrm{~A}$ & 145 & HE $550 \mathrm{~B}$ \\
\hline 21 & R 50 & 46 & SHS $180 \times 6.3$ & 71 & SHS $260 \times 6.3$ & 96 & $\mathrm{HE} 120 \mathrm{~A}$ & 121 & $\mathrm{HE} 280 \mathrm{~B}$ & 146 & HE $550 \mathrm{M}$ \\
\hline 22 & R 51 & 47 & SHS $180 \times 8$ & 72 & SHS $260 \times 8$ & 97 & HE $120 \mathrm{~B}$ & 122 & HE $280 \mathrm{M}$ & 147 & HE $600 \mathrm{~A}$ \\
\hline 23 & R 52 & 48 & SHS $180 \times 10$ & 73 & SHS $260 \times 10$ & 98 & HE $120 \mathrm{M}$ & 123 & HE $300 \mathrm{~A}$ & 148 & HE $600 \mathrm{~B}$ \\
\hline 24 & R 53 & 49 & SHS $180 \times 12.5$ & 74 & SHS $260 \times 12.5$ & 99 & $\mathrm{HE} 140 \mathrm{~A}$ & 124 & HE $300 \mathrm{~B}$ & 149 & HE $600 \mathrm{M}$ \\
\hline 25 & R 54 & 50 & SHS $180 \times 14.2$ & 75 & SHS $260 \times 14.2$ & 100 & HE $140 \mathrm{~B}$ & 125 & HE $300 \mathrm{M}$ & & \\
\hline
\end{tabular}
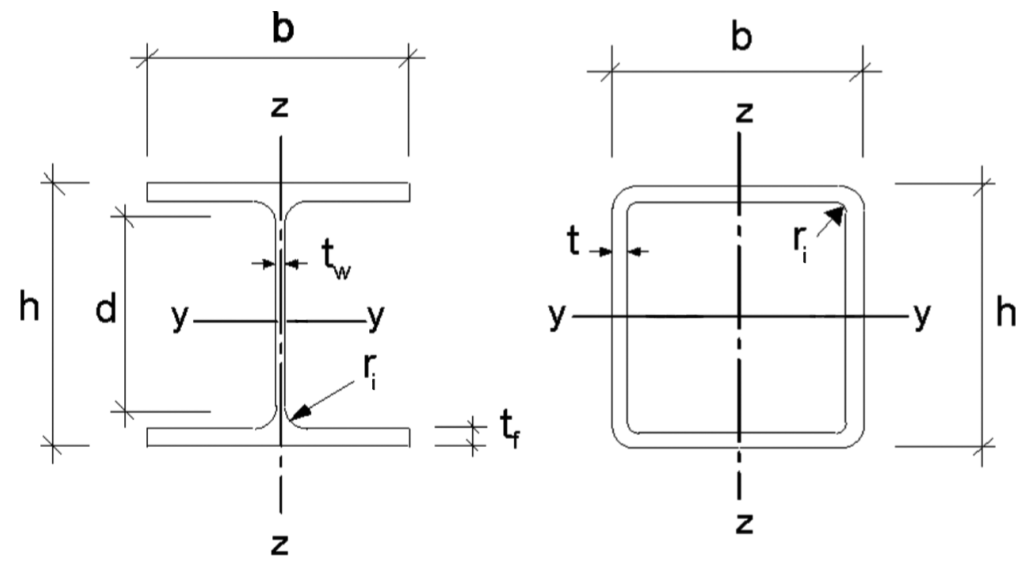

Figure B.14: Eurocode conventions for HE and SHS sections. 